\title{
Review
}

\section{Metastasis: cell-autonomous mechanisms versus contributions by the tumor microenvironment}

\author{
L. Kopfstein and G. Christofori*
}

Institute of Biochemistry and Genetics, Department of Clinical-Biological Sciences, University of Basel, Mattenstrasse 28, 4058 Basel (Switzerland), Fax: +41 61267 3566, e-mail: gerhard.christofori@unibas.ch

Received 4 July 2005; received after revision 3 November 2005; accepted 14 November 2005

Online First 16 January 2006

\begin{abstract}
The fatality of cancer predominantly results from the dissemination of primary tumor cells to distant sites and the subsequent formation of metastases. During tumor progression, some of the primary tumor cells as well as the tumor microenvironment undergo characteristic molecular changes, which are essential for the metastatic dissemination of tumor cells. In this review, we will discuss recent insights into pro-metastatic events occurring in tumor cells themselves and in the tumor stroma. Tumor cell-intrinsic alterations include the loss of cell polarity and alterations in cell-cell and cell-matrix
\end{abstract}

adhesion as well as deregulated receptor kinase signaling, which together support detachment, migration and invasion of tumor cells. On the other hand, the tumor stroma, including endothelial cells, fibroblasts and cells of the immune system, is engaged in an active molecular crosstalk within the tumor microenvironment. Subsequent activation of blood vessel and lymph vessel angiogenesis together with inflammatory and immune-suppressive responses further promotes cancer cell migration and invasion, as well as initiation of the metastatic process.

Key words: Angiogenesis; lymphangiogenesis; metastasis; tumorigenesis; tumor stroma.

\section{Introduction}

Carcinomas are the most frequent type of human malignancies, and the vast majority of cancer deaths are caused by the formation of metastases rather than by the primary tumor itself. Since existing metastases are difficult to target by conventional cancer therapies, a curative regimen requires the detection of the disease before the primary tumor has spread. Yet, despite evolving clinical diagnostic tools, a large proportion of tumors have already metastasized by the time of diagnosis.

The selective process of metastasis requires that cancer cells successfully complete several sequential, rate-limiting steps. They must detach from the primary tumor, invade the host stroma, intravasate into lymphatic or blood vessels, spread to the capillary bed of distant organs, ex-

\footnotetext{
* Corresponding author.
}

travasate and proliferate in the receptive organ parenchyma [1]. The succeeding metastatic cells have undergone changes in their proliferative, survival, migratory and invasive abilities and can be seen as winners of a 'metastasis decathlon' [2]. It is now well established that tumor cell-autonomous changes are not sufficient to allow tumor progression and metastasis to occur. By analogy with the architecture of organs, tumors are not only composed of a 'parenchyma' formed by the neoplastic cells, but also of a supportive 'stroma', consisting of specific extra-cellular matrix (ECM) components, fibroblasts, adipocytes, vascular cells, smooth muscle cells and cells of the haematopoietic system [3]. During tumor progression and metastasis, an active crosstalk occurs between tumor cells and their stroma, mainly mediated by direct cell-cell contact or paracrine cytokine and growth factor signaling, reminiscent of the communication between epithelial and mesenchymal cells during embryonic development. 
Such signaling may activate the tumor microenvironment at the primary and secondary tumor sites, thereby undergoing morphological changes (desmoplasia') and allowing or even supporting tumor outgrowth, invasion and metastasis [4]. Hence, tumor cell-stroma interaction is an important new focus of research in the treatment of metastatic disease.

Many excellent reviews cover particular aspects of molecular pathways known to be involved in the metastatic process. This review more broadly summarizes recent progress in the elucidation of various pro-metastatic molecular events and pathways occurring during tumor progression. In particular, we emphasize the distinction between tumor cell and tumor stroma contribution, and we discuss the role of tumor cell polarity, adhesion and deregulated receptor kinase signaling, as well as endothelial cells, fibroblasts and immune cells in invasion and metastatic dissemination of tumor cells.

\section{Tumor cell-intrinsic changes}

\section{Changes in cell-cell and cell-matrix adhesion}

\section{Loss of E-cadherin function and epithelial- mesenchymal transition}

E-cadherin is a central player in the makeup of cell polarity and epithelial organization. With its extracellular domains, this cadherin mediates calcium-dependent homophilic cell-cell contact in adhesion junctions, while linking adhesion junctions to the actin cytoskeleton via a cytoplasmic cell adhesion complex consisting of $\alpha$-, $\beta$-, $\gamma$ - and p120 catenins [5]. Thereby cell-cell adhesion can affect localization and function of cytoskeletal regulators and influence actin-guided cell motility [6]. In most cancers of epithelial origin, E-cadherin-mediated cell-cell adhesion is lost concomitantly with tumor progression and is correlated with advanced tumor grades and poor patient survival [7]. Consistent with this observation, forced downregulation of E-cadherin function in a mouse model of carcinogenesis promotes tumor progression, invasion and metastasis [8]. These and many more results from a variety of in vivo and in vitro experimental systems demonstrate that E-cadherin is an important molecule in tumor progression [5].

How does the loss of E-cadherin promote metastasis? In order to leave the coherent epithelial cell assembly of the primary tumor, malignant tumor cells have to acquire a fibroblastoid, migratory and invasive phenotype. A similar process physiologically occurs during embryonic development, tissue remodeling, wound healing and inflammation and is termed epithelial-to-mesenchymal transition (EMT) [9]. A number of in vitro studies (see below) collectively support the idea that morphologic and molecular changes of tumor cells required for the first
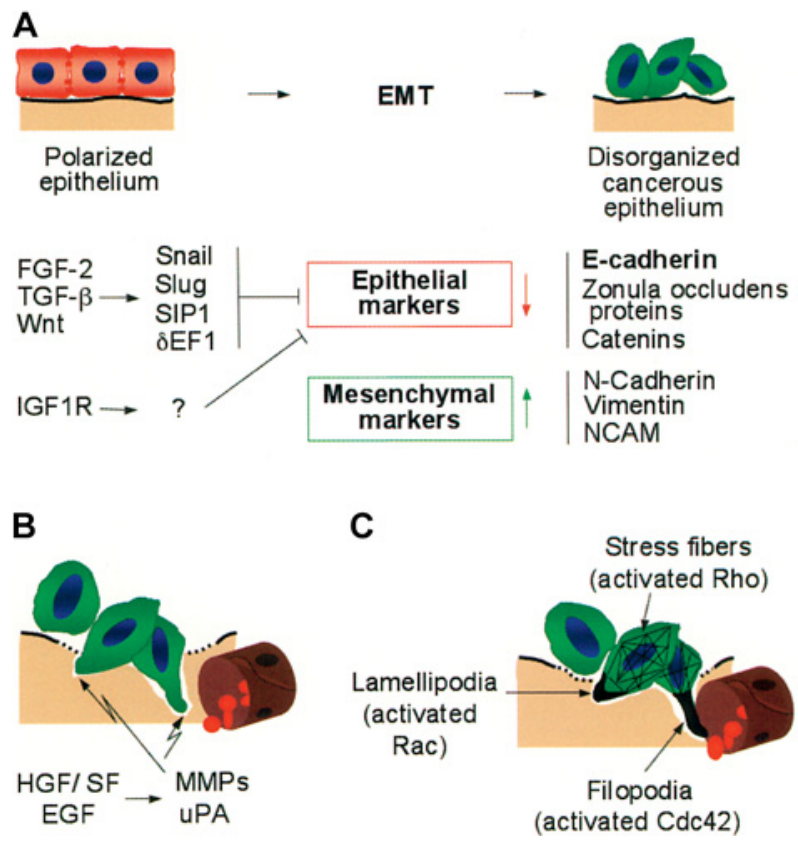

Figure 1. Mechanisms of tumor invasion and metastatic dissemination. During scattering and epithelial-to-mesenchymal transition (EMT), cells undergo major changes in morphology and lose cellcell contacts. (A) EMT of tumor cells. Loss of E-cadherin leads to disruption of adhesion junctions and is essential for EMT. TGF- $\beta$, FGF-2 and Wnt induce or stabilize Snail1, Snail2, $\delta$ EF1 and SIP1, all direct or indirect transcriptional repressors of E-cadherin. Concomitant with the loss of E-cadherin function, the expression of mesenchymal marker proteins is induced. $(B)$ Degradation of basement membrane (BM) and extra-cellular matrix (ECM). HGF/SF and EGF activate fibroblasts and endothelial cells to secrete matrix metalloproteases and urokinase-type plasminogen activator. The $\mathrm{BM}$ and ECM are thereby degraded, allowing tumor cells to transmigrate into the subepithelial ECM and to finally intravasate into blood or lymphatic vessels. (C) Activation of the tumor cell actin cytoskeleton, migration and invasion of metastatic cells into blood vessels. Upon loss of cell polarity, activated Rac, Cdc42 and RhoA are no longer sequestered at adhesion junctions and exert pro-migratory activities: Rac induces lamellipodia and membrane ruffles at the leading edge of the cell, Cdc42 bundles actin into filopodia, Rho assembles actin into stress fibers. These cytoskeletal changes result in increased cell motility.

steps of metastasis mimic physiological EMT. In fact, full EMT of in vitro cultured tumor cells is thought to resemble, at least in part, the metastatic process in cancer patients. Nevertheless, this hypothesis is still under debate and evidence for carcinoma EMT in vivo has yet to be found [10]. We support the view that EMT-like events occur in tumors and that studying these events may contribute to our understanding of metastasis formation.

Oncogenic events in tumor cells as well as growth factors secreted by tumor and stromal cells, including transforming growth factor- $\beta$ (TGF- $\beta$ ) and fibroblast growth factor 2 (FGF-2), induce EMT (fig. 1). During EMT, cells progressively redistribute or downregulate their apical and basolateral epithelial-specific proteins, such as tight and 
adherens junction proteins (including E-cadherin), and re-express mesenchymal molecules, such as vimentin and $\mathrm{N}$-cadherin. These changes lead to the abrogation of cellcell contacts and the gain of cell motility necessary for invasion (reviewed in [11]). EMT is in contrast to the process of cell scattering, where different epithelial markers are reversibly downregulated and expression of mesenchymal proteins is not induced. Scattering can be mediated by a number of growth factors, including hepatocyte growth factor/scatter factor (HGF/SF), TGF- $\beta$, FGF-2, TGF- $\alpha$ and epidermal growth factor (EGF) via the PI3K or the Raf/MAPK signaling pathways $[9,12]$.

Loss of E-cadherin promotes, whereas maintenance of its expression inhibits, EMT and metastasis [5, 8]. E-cadherin is therefore considered a metastasis suppressor gene. Downregulation of E-cadherin mostly occurs at the transcriptional level. The E-cadherin promoter is frequently repressed by specific transcriptional repressors, including Snail1 (previously Snail), Snail2 (previously Slug), SIP1, $\delta \mathrm{EF} 1$, Twist and E12/E47, and by subsequent promoter hypermethylation [13, 14]. Consistent with this observation, some of these repressors have been found expressed specifically at the invasive front of human invasive hepatocellular and breast carcinoma [15, 16]. The expression of these repressors seems to be highly regulated by pathways, including canonical Wnt signaling, TGF- $\beta$ (see below), FGF, EGF, Stat3 and nuclear factor $\kappa$-B (NF $\kappa-\mathrm{B})$ signaling [17-19]). Notably, Snaill is a highly unstable protein. It is rapidly phosphorylated by glycogen synthase kinase $3 \beta$ (GSK3 $\beta$ ) and subsequently ubiquitylated and degraded by the proteasome pathway [20]. As a result of transcriptional repression, the E-cadherin promoter is frequently found hypermethylated in a large subset of cancer cases [21]. E-cadherin can also be downregulated at the protein level. Receptor tyrosine kinases (RTKs), such as EGFR, cMet, IGF1R, FGFR and the non-receptor tyrosine kinase c-Src can induce phosphorylation of E-cadherin and catenins, resulting in their ubiquitylation by the E3 ligase Hakai and subsequent endocytosis and degradation [22-25]. Finally, secreted proteases such as matrix metalloprotease (MMP)-9, for example induced by TGF- $\beta$ and $\mathrm{HGF} / \mathrm{SF}$, can cleave E-cadherin and disrupt cadherin-mediated cell-cell contacts [26].

Loss of E-cadherin during EMT disrupts adhesion junctions between neighboring cells and thereby supports detachment of malignant cells from the epithelial cell layer. Yet, migration and invasion of tumor cells is also promoted by the loss of interaction of E-cadherin with the cytoskeleton, subsequent changes in the activities of Rho family GTPases, most prominently Rac1, Cdc42 and RhoA, and the concomitant reorganization of the actin cytoskeleton (fig. 1). In epithelial cells, E-cadherin-mediated assembly of adherens junctions recruits and activates Rac1 and Cdc42. Thereby, E-cadherin-bound $\alpha$ - and p120-catenin directly interact with Rho family-specific guanine nucleotide exchange factors (GEFs) and with Rho family members [27, 28]. Moreover, activated Rac1 and Cdc42 promote and consolidate E-cadherinmediated adhesion by sequestering their downstream effector IQGAP1, which in its free form inhibits the interaction of $\beta$-catenin with $\alpha$-catenin/E-cadherin [29]. After an early activation phase, where RhoA is required for Ecadherin clustering, RhoA gets gradually downregulated with a concomitant repression of cell migration [30]. In contrast, forced expression of RhoA (and also RhoC) in tumor cells induces focal adhesions and stress fibers, promoting invasion and metastasis [31, 32]. Upon loss of Ecadherin function, RhoA, Rac1 and Cdc42 are released from adhesion junctions and promote cell migration and invasion. Consistent with the dual role of these molecules, the Rac1-specific GEF Tiam1 localizes to adhesion junctions and promotes cell adhesion on substrates impeding cell migration (fibronectin, laminin), whereas it is found in lamellipodia when cells are cultured on cell motility-supporting collagen type I [33]. However, the mechanisms, by which ECM and thus integrin-mediated signaling affect the activity of RhoA, Rac1 and Cdc42, and with it E-cadherin function, remain to be elucidated. Recent studies have shown that mesenchymal cadherins, in particular N-cadherin, enhance tumor cell motility and migration (reviewed in [5]), thus exhibiting an opposite effect compared with E-cadherin. N-cadherin-induced tumor cell invasion can even overcome E-cadherin-mediated cell-cell adhesion. A novel concept based on the above observations is that a 'cadherin switch' from epithelial to mesenchymal cadherins exists which supports the transition from a benign to an invasive, malignant tumor phenotype. Hence, in addition to the loss of E-cadherin, the gain of $\mathrm{N}$-cadherin may critically contribute to tumor invasion and metastatic dissemination. In fact, Ncadherin has been shown to induce tumor cell migration, most likely by stimulating FGF receptor-mediated signal transduction $[34,35]$. Hence, changes in the expression of cadherins not only modulate cell-cell adhesion but also induce pro-metastatic signaling pathways.

\section{Integrins and tumor progression}

In order to detach and migrate, tumor cells depend on changes in both cell-cell and cell-matrix interactions. It is tacitly assumed that strong cell-matrix adhesions need to be dissolved, whereas transient and weak adhesions are a prerequisite for migration. This complex situation has made it difficult to experimentally determine the functional contribution of cell-matrix adhesion to tumor progression. With integrins being the prototype mediators of cell-matrix adhesion, they have been studied in great detail, also in tumor progression [36-38]. It is beyond the scope of this review to discuss the detailed mechanisms by which integrins affect tumor cell adhesion and migra- 
tion. Instead, we focus on the functional contribution of integrins to tumor metastasis. Moreover, the following sections present several mechanistic links of integrins to signaling pathways.

Integrins are heterodimeric cell surface receptors consisting of two type-I transmembrane subunits, $\alpha$ and $\beta$. They provide the essential link between the actin cytoskeleton and the ECM during cell migration. Different $\alpha$ and $\beta$ subunits form distinct integrin subtypes, which link ECM ligands, such as fibronectin, vitronectin, laminin and collagen, to the intracellular actin cytoskeleton [38]. Importantly, binding to these ECM components activates integrins, which in turn induce intracellular signaling cascades modulating cell proliferation, survival, polarity, motility and differentiation $[36,38,39]$. Thereby integrins mediate anchorage dependence, since they allow these processes only in appropriately adhering cells. However, during tumor progression, mutations in oncogenes and tumor-suppressor genes can enable non-adherent neoplastic cells to survive and proliferate in the absence of proper cell-matrix adhesion [40]. Cancer cells that profit from integrin signals are being selected due to their survival and proliferation advantage. Many cancer types, including melanoma, glioblastoma, prostate, breast and ovarian cancer, exhibit increased expression of $\alpha_{v} \beta_{3}, \alpha_{2} \beta_{1}, \alpha_{4} \beta_{1}$ and $\alpha_{6} \beta_{1}$ integrins during tumor progression [41-43]. Tumor cell migration and metastasis is supported by integrin-mediated focal adhesion and actinomyosin-dependent contractility, as demonstrated for instance for integrins $\alpha_{6} \beta_{4}, \alpha_{2} \beta_{1}$ and $\alpha_{\mathrm{v}} \beta_{3}$ [44-46]. Furthermore, activated integrins can recruit proteases, such as MMP-9, towards the site of attachment, and the subsequent ECM degradation supports migration and invasion of cells into the surrounding tissue [38, 43]. Unfortunately, various subsets of integrins seem to mediate different functions during progression of different cancer types, and more experimental work will be required to unravel their actual functional contribution.

Endothelial cell integrins have been studied in great detail during physiological and pathological angiogenesis and have been shown to play an important role in tumor angiogenesis. Distinct subtypes, including $\alpha_{1} \beta_{1}$ and $\alpha_{2} \beta_{1}$ integrins, support vascular endothelial growth factor (VEGF)-mediated angiogenesis in tumor xenotransplantion experiments [47]. Endothelial $\alpha_{5} \beta_{1}, \alpha_{\mathrm{v}} \beta_{3}$ and $\alpha_{\mathrm{v}} \beta_{5}$ integrins are critically involved in both VEGF- and FGFmediated angiogenesis. Peptide antagonists against these integrins are able to interfere with tumor angiogenesis in a number of experimental model systems, and initial clinical trials with some of these compounds are under way [37]. Interestingly, experiments with mice lacking $\alpha_{\mathrm{v}} \beta_{3}$ and $\alpha_{\mathrm{v}} \beta_{5}$ integrins have demonstrated increased rather than reduced tumor growth, raising the possibility of a dual function of integrins at least in the angiogenic process [48]. Thus, changes in integrin-mediated matrix adhesion on tumor cells, endothelial cells and certainly other cells of the tumor stroma can influence tumor cell migration, invasion and angiogenesis, all rate-limiting processes in tumor metastasis.

\section{Immunoglobulin family adhesion molecules: NCAM and L1}

Among many other cell adhesion molecules (CAMs), two have been specifically implicated in promoting tumor cell invasion and metastatic spread, NCAM (CD56) and L1 (CD171, L1CAM). Both structurally belong to the immunoglobulin (Ig) superfamily and are critical for central nervous system (CNS) development. They not only mediate static neuron-neuron adhesion but also are particularly involved in neurite outgrowth, axon guidance and neural cell migration. In addition to providing mechanical cell-cell and cell-ECM adhesion, they also activate signaling receptors and induce intracellular signaling cascades $[5,49]$.

NCAM has been shown to play an important role in the progression to tumor malignancy. Both the shift of the adult NCAM $120-\mathrm{kDa}$ isoform to the embryonic 140and $180-\mathrm{kDa}$ isoforms and a general downregulation of NCAM expression are associated with poor prognosis in a few cancer types [50, 51]. In a transgenic mouse tumor model of pancreatic $\beta$ cell carcinogenesis (Rip1Tag2), loss of NCAM leads to the formation of lymph node metastasis mediated by the increased expression of the lymphangiogenic factors VEGF-C and D and with it upregulated peri-tumoral lymphangiogenesis $[52,53]$. Similar to its function in neurons, NCAM also modulates cell-matrix adhesion of tumor cells by binding to FGFR and inducing a variety of signaling pathways that lead to $\beta_{1}$ integrin-mediated cell-matrix adhesion and neurite outgrowth [34].

While L1 exerts functions similar to NCAM in neurons, L1 is specifically expressed at the invasive front of gliomas, melanomas, lung, prostate, renal, ovarian and endometrial carcinoma, and its expression appears to correlate with metastasis [54-59]. Similar to NCAM, L1 has been shown to enhance migration and invasion of tumor cells in vitro. L1 promotes cell-matrix adhesion and migration of tumor cells on ECM proteins, such as fibronectin and laminin, by associating with integrins through an integrin recognition motif. Namely, integrins $\alpha_{v} \beta_{5}, \alpha_{v} \beta_{3}$ and $\alpha_{5} \beta_{1}$ have been found to associate with L1 [49, 60$62]$. In these studies, integrin-mediated signaling events induced by associated L1 seem to be responsible for promoted cell migration. Interestingly, L1-integrin interaction may not only occur in cis at the cell surface but also by ectodomain shedding of L1 and subsequent autocrine/ paracrine binding of soluble L1 to $\alpha v \beta 5$ integrin. Independent of integrin binding and activation, L1 has also been shown to promote growth factor-induced mitogenactivated protein kinase (MAPK) signaling and to subse- 
quently stimulate extracellular regulated kinase (Erk)1/2mediated transcriptional changes in genes associated with cell motility and invasion and matrix remodeling [49]. Such targets include the genes for cathepsin-L and -B, osteopontin (OPN), RhoC and CD44, all proteins implicated in tumor invasion and metastasis (CD44 and RhoC are discussed below) [49, 63]. Finally, L1 was recently identified as a direct target gene of activated Wnt signaling, together with the metalloprotease ADAM10. Co-induction of ADAM10 and L1 leads to proteolytic shedding of the L1 extracellular domain, which in turn induces tumor cell motility and enhanced tumorigenesis [64].

Together, these selected examples indicate that detachment and migration of tumor cells critically depends on altered cell-cell and cell-matrix adhesion. Yet, such alterations appear not to only affect cell adhesion but also a variety of signal transduction pathways, mediated by tyrosine kinase receptors or by integrins, which all seem to lead to increased tumor cell invasiveness and metastatic dissemination.

\section{Changes in signaling pathways during EMT and scattering}

Malignant transformation with deregulation of cell growth is frequently induced by somatic mutations or overexpression of receptor tyrosine kinases [65]. Importantly, deregulated signaling of some receptor tyrosine kinases not only exerts transformation of tumor cells but also promotes their invasion and metastatic dissemination. The following sections address some of the newly emerging aspects of how receptor tyrosine kinases contribute to tumor metastasis (fig. 1).

\section{c-Met and hepatocyte growth factor/scatter factor (HGF/SF)}

Overexpression of and activating mutations in c-Met have been reported in many human tumors, and xenotransplant and transgenic mouse models demonstrate a profound pro-metastatic activity of HGF/SF and c-Met [66-68]. cMet, encoded by the MET proto-oncogene, is a dimeric transmembrane tyrosine kinase receptor for HGF/SF. Intracellular transducers of c-Met activity include Ras/ MAPK, PI3K, phospholipase $\gamma$ (PLC- $\gamma$ ), Src-related tyrosine kinases and growth-factor-receptor-bound protein 2 (Grb2)-associated binder 1 (Gab-1). Internalization is a typical mechanism by which signaling of receptors such as c-Met is terminated, and poly-ubiquitylation promoted by c-Cbl is critical for c-Met downregulation by targeting it to the proteasome $[69,70]$.

Although the precise mechanisms underlying c-Met-mediated tumor cell migration and invasion are not completely understood, several critical events have been recently elucidated. Upon ligand binding, c-Met induces invasive growth, both during physiological tissue morph- ogenesis and tumor progression. HGF/SF-mediated effects appear to depend on the differentiation state of the c-Met-expressing cells. Whereas HGF/SF induces morphogenesis of E-cadherin-positive polarized epithelial cells, it promotes scattering and metastasis of cells that have lost their epithelial characteristics [69]. The metastatic potential of c-Met is mediated via a signal transducer docking site, which can bind and activate multiple Src homology region 2 ( $\mathrm{SH} 2$ )-containing intracellular effectors. Interestingly, a distinct mutation of this domain $(\mathrm{H} 1351 \mathrm{~N})$ increases the transforming but in parallel abolishes the metastatic properties of c-Met [71]. c-Met-induced dissociation of adherens junctions, scattering and metastasis appear to be primarily mediated via the PI3K pathway in a MAPK-dependent, yet protein kinase B (PKB/Akt)- or Rac-independent manner [72, 73]. Through activation of the MAPK pathway, c-Met signaling induces Ets 1 transcription factors, which control the expression of genes involved in ECM remodeling and cell scattering [74]. In fact, Ets 1 expression is known to correlate with metastasis incidence in a number of cancer types $[75,76]$.

Recent results indicate that the pro-metastatic activity of c-Met also critically depends on its ability to associate with other cell surface proteins, notably $\alpha_{6} \beta_{4}$ integrin, CD44 and Plexin B1. c-Met is constitutively associated with integrin $\alpha_{6} \beta_{4}$, which in turn is phosphorylated by activated c-Met. Subsequently, phosphorylated integrin $\alpha_{6} \beta_{4}$ recruits the signaling adaptor Shc and PI3K and potentiates HGF/SF-induced activation of the Ras and PI3K pathways [77]. c-Met also associates with and is functionally modulated by $\mathrm{CD} 44$, a hyaluronan receptor involved in cell-cell/cell-matrix interactions, cell migration and metastasis [78]. Upon HGF/SF stimulation, cMet associates with a variant CD44 isoform (CD44v6) and recruits ezrin, radixin and moesin proteins (ERMs) to the complex [79]. ERMs link adhesion molecules to filamentous F-actin and participate in membrane and cytoskeletal remodeling during cell migration. Both CD44 and the ERM proteins are known to promote metastasis by various mechanisms. For instance, ezrin can stabilize mammalian target of rapamycin (mTOR) downstream signaling molecules, enhancing metastasis [80]. c-Metmediated tumor cell invasion is CD44-dependent and may also require ERMs, since signal transduction by activated c-Met via the MAPK pathways depends on the ERM binding domain of CD44 [79, 81, 82]. Furthermore, HGF/SF specifically induces the expression of OPN and its association with the hyaluronan-CD44ERM complex at the leading edge of metastatic cells [83, 84]. OPN is a protein of the ECM with a wide variety of cell surface binding proteins and has been shown to promote tumor cell invasiveness [85]. The functional cooperation of c-Met, CD44 and OPN thus may be critical for metastasis [83]. 
Plexins, which share structural homology with c-Met, are widely expressed receptors for Semaphorins (Sema). The Sema family consists of secreted and membrane-bound members that act as guidance signals for neurons [86, 87]. Recently, Plexin B1 has been shown to be overexpressed in several tumor cell lines and to be physically associated with c-Met [87]. Notably, binding of Sema 4D to Plexin B1 transactivates the tyrosine kinase activity of cMet independent of the presence of HGF/SF [88]. Interestingly, the identical signaling pathway in endothelial cells leads to angiogenesis [89].

In addition to inducing a motile tumor cell phenotype, cMet promotes invasion of neoplastic cells by upregulating proteases such as plasminogen activator (UPA) and MMPs via MAPK and PKC, respectively. These proteases are critical in degrading the ECM and allowing migration of tumor cells through the basement membrane and the surrounding stroma [90].

Based on the multitude of activities and interactions during tumor progression, c-Met represents an important mediator of cell migration and metastasis and, hence, cMet-mediated signaling pathways are in the spotlight as potential targets for the development of anti-metastatic therapy [91].

\section{Wnt signaling and tumor progression}

In many cancer types, Wnt signaling is activated by mutations in a number of effector genes, including the genes encoding for adenomatous polyposis coli (APC), axin-1 and 2 , and $\beta$-catenin, which predispose to cancer [92-94]. Besides their critical role in assembling the E-cadherinmediated cell adhesion complex, $\beta$-catenin and $\gamma$-catenin also have important functions in the canonical Wnt-signaling pathway. Non-sequestered, free $\beta$ - and $\gamma$-catenin are rapidly phosphorylated by GSK- $3 \beta$ in the APC/axin/ GSK- $3 \beta$ complex and subsequently degraded by the ubiquitin-proteasome pathway. If the tumor suppressor APC is non-functional, as in many colon-cancer cells, or if GSK- $3 \beta$ activity is blocked by the activated Wnt-signaling pathway, $\beta$-catenin accumulates at high levels in the cytoplasm. Subsequently, it translocates to the nucleus, where it binds to members of the Tcf/Lef-1 family of transcription factors and modulates the expression of Tcf/Lef-1-target genes, including c-Myc, cyclin D1, fibronectin, MMP-7, Id2, CD44, axin-2, Tcf-1 and others, all genes implicated in cell proliferation, transformation and tumor progression.

The dual function of $\beta$-catenin has motivated a multitude of experiments to assess whether the loss of E-cadherin function would subsequently lead to the activation of the Wnt-signaling pathway. In a number of cellular systems, it has been demonstrated that sequestration of $\beta$-catenin by E-cadherin can compete with the $\beta$-catenin/TCF-mediated transcriptional activity of the canonical Wnt-signaling pathway. The fact that E-cadherin does not com- pletely deplete the cytoplasmic $\beta$-catenin suggests that $\beta$ catenin exists in different functional pools $[95,96]$. Interestingly, in breast and prostate carcinoma cell lines, Ecadherin suppresses tumor cell invasion by binding $\beta$ catenin without repressing $\beta$-catenin/TCF transcriptional activity, indicating that a novel, as yet unknown, additional function of $\beta$-catenin may be required for cellular invasiveness [97, 98].

Furthermore, activated Wnt signaling inhibits E-cadherin-mediated cell adhesion by inducing expression of Snaill, a transcriptional E-cadherin repressor. Snaill in turn synergizes with the $\mathrm{Wnt} / \beta$-catenin pathway by inducing Tcf expression, and $\beta$-catenin/Tcf can in turn repress E-cadherin transcription in co-operation with Snaill $[99,100]$.

\section{Signals elicited by ErbB receptors}

Many metastatic human carcinomas are characterized by the overexpression or constitutive activation of ErbB tyrosine kinase receptor (EGFR) family members involving activating mutations of the receptor kinases or an autocrine loop with EGF family ligands. In addition to stimulating cell differentiation and proliferation, EGF promotes tumor cell motility, invasion and metastasis by affecting a large number of protein functions and signaling pathways, including Wnt signaling, Snaill expression, focal adhesion kinase (FAK) activity and expression of MMPs [101].

Interestingly, ErbB receptors and Wnt signaling cooperate during tumorigenesis, which may be critical for metastasis formation [102]. In tumors of mouse mammary tumor virus (MMTV)-Wnt-1 transgenic mice, two members of the ErbB family of transmembrane receptor tyrosine kinases, ErbB1 (EGF receptor) and ErbB2 (Her-2/c$\mathrm{Neu}$ ), interact with and phosphorylate $\beta$-catenin. Interestingly, the $\beta$-catenin/ErbB interaction correlates with the incidence of pulmonary metastases, indicating a functional role of these interactions in metastasis formation [102]. Tyrosine phosphorylation of $\beta$-catenin by ErbB1 and by other receptor tyrosine kinases is known to destabilize its binding to E-cadherin. As a result, adhesion junctions disassemble, the liberated $\beta$-catenin accumulates in the cytoplasm, transfers to the nucleus and, in combination with Tcf/Lef1 transcription factors, modulates gene expression. Such activation of the Wnt pathway may result in increased tumor cell migration, invasion and metastasis (reviewed in [103]).

Notably, Snail1 and caveolin-1 seem to play antagonistic roles during EMT induced by EGF. Caveolins are structural proteins of caveolae, the invaginations of the plasma membrane that function as regulators of signal transduction. Transient EGF signaling induces caveolin1-dependent endocytosis of E-cadherin. Long-term EGF treatment downregulates caveolin-1 and induces Snail1. Concomitantly, $\beta$-catenin/Tcf/Lef-1 transcriptional ac- 
tivity is enhanced [19]. Interestingly, both EGF-mediated upregulation of Snaill transcription as well as increased transactivation by $\beta$-catenin are dependent on caveolin-1 downregulation. EGF-induced downregulation of caveolin-1 may therefore play a central role in invasion and metastasis.

\section{Insulin-like growth factor 1 receptor (IGF1R)}

Insulin-like growth factors (IGFs) and their cognate signaling receptor IGF1R are involved in cellular and organismal growth, embryonic development and numerous pathological states, including cancer and metastasis [104]. IGF1R overexpression in the primary tumor correlates with the increased incidence of metastases in patients with gastric cancer, gastrinoma, gastrointestinal stromal tumors, thyroid cancer and other malignancies [105-108]. Forced expression of IGF1R in a transgenic mouse model of pancreatic $\beta$ cell carcinogenesis (Rip1Tag2) results in accelerated tumor progression, with increased tumor malignancy and distant tumor metastasis to various organs [109]. Conversely, a small chemical inhibitor of IGF1R tyrosine kinase activity (NVP-AEW541) is able to repress tumor cell survival and tumor growth of a number of different tumor types in culture or in xenograft transplantation experiments, yet its effects on tumor progression and metastasis have not been explicitly assessed $[110,111]$.

The mechanisms of IGF1R-mediated invasive and metastatic abilities of tumor cells have been recently studied. IGF1R signaling has been famous for mediating anti-apoptotic and mitogenic effects via PI3K/PKB and Ras/MAPK pathways. Yet, IGF1R also modulates cellsubstrate adhesion, migration, invasion and cell-cell interaction by signaling via FAK $[112,113]$. IGF1R has also been shown to modulate the expression and function of different junctional proteins, including cadherins, catenins, ZO-1 and the small GTPases RhoA, Rac1 and Cdc42 [114]. Notably, upon IGF-II binding, activated IGF1R associates with E-cadherin and $\beta$-catenin, thereby inducing reversible scattering [115]. Through internalization of the entire complex, E-cadherin is sequestered from the plasma membrane and targeted to late endosomes and lysosomes. As a consequence, the released $\beta$ catenin translocates to the nucleus and induces Tcf/Lef1mediated transcription of target genes (see also the previous sections). Conversely, overexpression of E-cadherin antagonizes the effects of IGF-II. Such mechanisms are currently being investigated to resolve the actual contribution of IGF1R to tumor metastasis.

\section{TGF- $\beta$ signaling}

TGF- $\beta$ is a member of the TGF- $\beta$ superfamily of ligands and binds to a heterodimeric receptor consisting of type I and II transmembrane receptor serine-threonine kinases. TGF- $\beta$-mediated activation of the receptors induces a canonical signaling pathway via Smad proteins, which re- sults in nuclear translocation of receptor-Smads (Smad2/ 3) together with common-Smad (Smad4) and in the modulation of expression of various target genes [116, 117]. Depending on the cell type, alternative signaling pathways, including MAPK, PI3K and PKC, can also be activated [118-120].

Depending on the differentiation and transformation status of a cell, TGF- $\beta$ exerts two directly opposing functions; it acts as an anti-proliferative and pro-apoptotic growth factor on differentiated cells, but induces proliferation and EMT of undifferentiated or transformed cells. Hence, at early stages of tumor development, TGF- $\beta$ 's cytostatic action helps to suppress tumor growth. At later tumor stages, however, transformed cells develop resistance to the growth-inhibitory effect of TGF- $\beta$ and respond to TGF- $\beta$ by undergoing EMT (reviewed in [121]). Moreover, TGF- $\beta$ exerts immunosuppressive functions that further promote tumor progression.

Resistance of tumor cells to TGF- $\beta$-mediated growth restraint and induction of EMT is mostly due to functional changes downstream of the TGF- $\beta$ signaling pathway [9]. At the transcriptional level, TGF- $\beta$ cooperates with various signaling pathways stimulated by EGF, interferon $\gamma$ (IFN $\gamma$ ) and tumor necrosis factor (TNF)- $\alpha$. Activated MAPK signaling, for instance, can inactivate Smads, induce inhibitory Smads or induce an autocrine TGF- $\beta$ production (for detailed reviews see [117, 122]). In immortalized (non-transformed) mammary epithelial EpH4 cells, oncogenic Ras and TGF- $\beta$ R signaling are required for the induction and maintenance of TGF- $\beta$-induced EMT [123]. In Ha-Ras-transformed EpH4 cells (EpRas), upregulation of the PI3K pathway prevents TGF- $\beta$-induced apoptosis and promotes scattering. Full EMT, however, depends on the activation of the MAPK pathway. Similarly, an activated PI3K pathway correlates with tumor formation of these cells, whereas a hyperactive MAPK pathway is required for both tumorigenesis and metastasis $[9,12])$. Moreover, TGF- $\beta$-induced EMT seems to depend on $\beta_{1}$ integrin-mediated signals and RhoA-induced actin cytoskeleton rearrangements [124]. Such cooperative activities of TGF- $\beta$ together with its dual role as tumor promoter and tumor suppressor obscure a direct therapeutic exploitation of this pathway and stimulate further studies into the mechanistic details of these activities.

\section{Genes mediating metastasis}

An ongoing interesting debate in the field of cancer metastasis concerns the question whether the metastatic potential of a tumor cell is primed with the first initial genetic events of transformation or whether tumor cells by clonal selection progress to tumor malignancy. It seems that genetic alterations acquired early during tumorigenesis (including gain of oncogenes and loss of tumor-sup- 
pressor genes) are sufficient for certain tumor cells to spread $[125,126]$. For instance, gene microarray analysis has identified specific expression profiles in metastatic versus non-metastatic primary human carcinomas [127130]. Yet, the pro-metastatic efficacy of those genes remains to be shown. On the other hand, circulating tumor cells are found to carry various genetic alterations, suggesting that additional genetic events are required for tumor cell dissemination [131]. Moreover, many genes are expressed and seem to be functional only during the metastatic process. Even more impressive, transgenic expression of MMP3 is sufficient to induce full-blown carcinogenesis, indicating that 'invasive or metastatic' processes can even affect the transformation status of a cell [132].

More refined approaches of gene expression analysis combined with functional experiments have now provided novel insights into such events. For example, work published this year has not only identified genes that may specifically mediate lung metastasis of breast cancer cells but also confirmed their pro-metastatic functionality in vitro and in vivo [133]. The genes were tested by overexpression in poorly metastatic cells or by RNA interference (RNAi) knock-down in highly metastatic cells. These were observed to specifically metastasize to the lung and not the bone when orthotopically injected into the mammary fat pad of immunodeficient mice. Nine genes have been found to be overexpressed in cells mediating lung metastagenicity in in vivo experiments, encoding the pan-ErbB receptor ligand epiregulin, the chemokine CXCL1, the interleukin decoy receptor IL13R $\alpha 2$, the proteases MMP1 and 2, cyclooxygenase-2 (COX2), the transcriptional inhibitor of cell differentiation-1 (ID1) and the cell adhesion molecules VCAM1 and SPARC [133]. Recently, the chemokine receptor CXCR4 was shown to be highly expressed in breast cancer cells, primary breast tumors and metastases. Its ligand CXCL12/ stromal cell-derived factor (SDF) $1 \alpha$, on the other hand, is predominantly found in organs known to be the main targets of breast cancer metastasis, namely lymph nodes, lung, bone marrow and liver. Notably, treatment with neutralizing antibodies against CXCR4 reduced the capability of a metastatic breast cancer cell line to metastasize to lymph nodes and the lung [134].

Several other genes with various functions have been identified in different gene expression profiling experiments on non-metastatic versus metastatic tumor cell lines. Some of these are already confirmed as being required for metastasis in vivo. For instance, the transcriptional repressor Twist is overexpressed in human invasive lobular breast cancer and has been shown to abrogate E-cadherin-mediated cellcell adhesion as well as to induce EMT in vitro. RNAi knock-down of Twist in a highly metastatic breast cancer cell line reduces the number of circulating tumor cells in the blood vasculature and dramatically decreases the inci- dence of lung metastases when tumor cells are injected orthotopically in the mammary fat pad [135].

The neurotrophic tyrosine kinase receptor TrkB has been identified as a potent metastasis-inducing gene in an elegant expression cloning experiment [136]. TrkB specifically suppresses caspase-induced anoikis of non-malignant epithelial cells. Anoikis is a physiological mechanism eliminating cells that have lost an adequate interaction with the ECM, a process that is apparently repressed in metastasizing cells. Forced expression of TrkB in normal epithelial cells confers resistance to anoikis and allows their metastatic growth in the lung and heart upon tail vein injection into nude mice. Cells expressing both TrkB and its ligand BDNF even cause metastasis throughout the body. In contrast, controltransfected epithelial cells colonize these organs but undergo apoptosis after a short period of time [136].

Rho-family GTPases function in cytoskeletal reorganization, cell migration, stress fiber formation and focal adhesion [137]. It is not surprising that enhanced expression of one of the Rho GTPase family members, RhoC, correlates with the progression of various tumor types to a metastatic phenotype [138, 139]. In gene expression profiling experiments with melanoma variants of low or high metastatic potential, RhoC has been identified as a candidate involved in the spread of malignant cells. In fact, melanoma cells expressing high levels of RhoC show a markedly increased metastatic potential compared with control cells [32]. Cells lacking RhoC display reduced motility and invasiveness in vitro. Moreover, when crossed to RhoC-deficient mice, transgenic mice developing metastatic breast cancer (MMTV-PymT) exhibit a significant decrease in metastasis together with increased apoptosis of disseminating cells [140].

Protease-activated receptors (PARs) constitute a family of G-protein-coupled receptors and are involved in various physiological processes. They are frequently expressed in the context of metastasis and are currently subject to intense research. PARs seem to be causally involved in the metastatic process of many human cancers, and a clear pro-migratory and pro-metastatic effect has been demonstrated for PAR1 in vitro and in vivo [141]. Activating cleavage of PAR1 by various proteases induces increased migration and invasion of cells, notably by the engagement of $\alpha_{\mathrm{v}} \beta_{5}$ integrins and changes in cell adhesion [142]. In a xenograft mouse model, expression of PAR1 is both required and sufficient to promote growth and invasion of breast carcinoma cells. In this model, fibroblast-derived MMP1 cleaves and activates PAR1, thereby inducing $\mathrm{Ca}^{+}-$ dependent signaling and promoting tumor cell migration and invasion [141]. Proteases known to activate PAR1 and 2 include thrombin and plasmin, which may account for one mechanism by which the coagulation system, frequently activated during tumorigenesis, promotes cancer cell motility and metastasis $[143,144]$. 
Some of the above-mentioned genes may not only be useful predictive screening markers for cancer patients in order to adapt a more or less aggressive therapy, but may also serve as potential targets for anti-metastatic measures. Fortunately, the number of genes and factors involved in cancer metastasis is growing daily, and, after adequate functional characterization, a number of useful novel therapeutic targets can be expected.

\section{Metastasis-promoting activities of the tumor microenvironment}

Mounting evidence from various experimental systems has demonstrated in the past years that the tumor microenvironment contributes in a pivotal way not only to tumor initiation but also to tumor progression. Normal stroma modulates cell homeostasis in order to exert tissue-specific physiological functions and to prevent inappropriate growth, apoptosis and differentiation. In contrast, aberrant stroma supports de-differentiation and transformation of cells. Tumor formation thus depends on both tumor cell-intrinsic genetic events and changes in the tumor microenvironment [40, 145].

In the following chapters, we call attention to cells of the tumor stroma and discuss some selected examples of the molecular mechanisms by which the tumor microenvironment promotes tumor cell invasiveness and spread to distant organs (fig. 2).

\section{Tumor angiogenesis}

The entry of tumor cells into blood vessels (intravasation) initiates dissemination of cancer cells from the primary tumor to distant organs via the blood vasculature (hematogenous metastasis). This first step not only depends on tumor-cell-intrinsic invasive properties but obviously also on the presence of a tumoral vascular network, which itself constitutes part of the tumor stroma. Stimulated sprouting of new tumor blood vessels from a pre-existing vascular network (angiogenesis) represents a risk factor for the development of distant metastases in at least two ways. First, an increasing number of tumor blood vessels augment the contact area between tumor cells and their potential escape routes, thereby increasing the probability of intravasation. Second, tumor blood vessels display a distinct morphology in comparison to the physiological vascular bed, facilitating entry of cells: they are larger, tortuous and leaky due to a fragmented basement membrane and an incomplete pericyte lining [146]. Furthermore, hematogenous spread of cancer cells can also occur as a result of lymphogenous metastasis. Since the lymph is drained into the venous system and lymph nodes display afferent and efferent blood vessels, tumor cells circulating in the lymphatic vasculature can successively enter the systemic circulation.

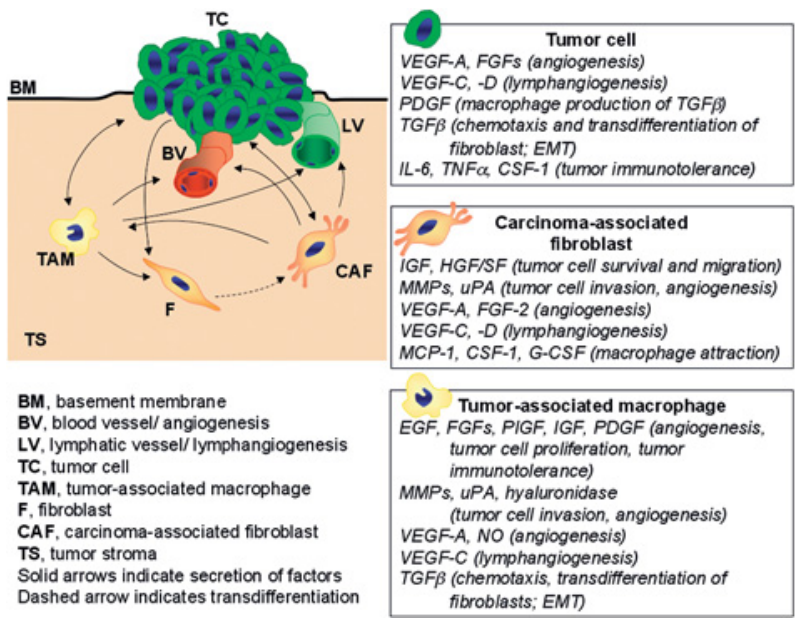

Figure 2. Contribution by the tumor microenvironment. Stromal and tumor cells cross-talk via soluble growth factors, cytokines and chemokines as schematically exemplified in this figure for tumorassociated macrophages (TAMs) and carcinoma-associated fibroblasts (CAFs). Stromal cells and tumor cells thus mutually influence their behavior in a way that promotes metastasis. For instance, tumor cell-secreted PDGF stimulates macrophages to produce TGF$\beta$, which induces the transdifferentiation of fibroblasts into CAFs. CAFs in turn secrete macrophage chemoattractants, which promote the infiltration of macrophages into the tumor. Both TAMs and CAFs secrete growth factors, cytokines and proteases, which promote tumor cell survival, migration and invasion into the surrounding tissue. Moreover, a variety of tumor and stromal cell-secreted factors induce the formation of blood and lymphatic vessels and also modulate the immune system to tolerate the transformed cells.

Angiogenesis is orchestrated by a fine-tuned balance between secreted pro- and anti-angiogenic factors [147]. The contribution of the tumor stroma to the regulation of angiogenesis has also complicated the simplistic view that angiogenesis is mainly induced by transforming signaling pathways and by tumor hypoxia, resulting in the tumor cells' expression of angiogenic factors, such as VEGF-A and PIGF. Rather, several cell types of the tumor stroma appear to contribute in a significant way: (i) endothelial cells by secreting angiogenic factors, such as angiopoietin-2, which affect the activation status of the endothelium and its differentiation into mature vessels, (ii) infiltrating macrophages and mast cells by secreting additional angiogenic factors, including VEGF-A, FGF2 , TGF- $\beta$ and IL- 8 , and MMPs that activate latent forms of these growth factors, (iii) cancer-associated fibroblasts (CAFs) by secreting additional growth factors, cytokines and chemokines and by modulating the ECM and (iv) additional cells of the innate and adaptive immune system or of tissue homeostasis (see below) [148, 149].

During tumor outgrowth, tumor cells and cells of the tumor stroma are stimulated for example by tumor hypoxia or lack of nutrition to produce angiogenic factors, such as VEGF-A and PlGF. These factors, together with various inflammatory chemokines and cytokines and other stimuli secreted by both neoplastic and tumor stroma 
cells, tilt the balance between angiogenesis inhibitors and inducers towards the stimulation of angiogenesis (angiogenic switch). Thereby, tumor-cell and tumorstroma-induced angiogenesis not only promotes primary (and secondary) tumor growth, but also the hematogenous dissemination of tumor cells and the outgrowth of metastasis.

Most, though not all, clinical studies demonstrate a direct correlation of high primary tumor blood microvessel densities (MVDs) with increased incidence of metastases $[150,151]$. Tumor MVD is a significant and independent prognostic indicator for relapse-free and overall survival of cancer patients [152]. Similarly, elevated tumor or serum levels of the pro-angiogenic factors VEGF-A, interleukin (IL) and FGF-2 as well as a low ratio between the angiogenesis inhibitor thrombospondin-2 and VEGF-A are associated with an increased incidence of metastasis in cancer patients [153155]. Xenograft animal models confirm the correlation of tumoral overexpression of angiogenic growth factors, increased MVD of primary and secondary tumors and metastasis formation [156-158]. Consistent with these results, transgenic mice developing prostate adenocarcinoma (TRAMP) exhibit impaired metastasis when crossed into a FGF-2 knockout background [159]. Similarly, in xenotransplant and transgenic mouse models, increased tumor and/or serum levels of angiogenesis inhibitors, such as IL-10, tissue inhibitor-1 of metalloproteinases (TIMP-1), thrombospondin-1 or endostatin, reduce the incidence of metastasis [158, 160-162]. Yet, upregulated tumor angiogenesis may not necessarily lead to metastasis formation. For example, forced expression of VEGF-A in a transgenic mouse model (Rip1Tag2) accelerates tumor angiogenesis and growth of primary tumors but does not result in increased metastasis formation [163]. Although tumorigenic transformation, mediated for example by Ras or ErbB2, can upregulate the expression of angiogenic growth factors and repress the production of anti-angiogenic molecules, the direct contribution of the angiogenic process to tumor metastasis is difficult to demonstrate [164]. Inhibition of angiogenesis during tumor progression by specific angiogenesis inhibitors also affects primary tumor growth and thus indirectly the metastatic dissemination of tumor cells. One should also be aware of the observation that intra-tumoral hypoxia and concomitant upregulation of the expression of angiogenic factors may occur only intermittently, leading to variations in the expression in tumors and in serum levels at different time points of measurement. Moreover, methods and markers for the determination of MVD have not been standardized, hindering a direct comparison of independent studies [165]. In any case, interference with angiogenesis will not only lead to a repression of tumor growth but may also reduce tumor metastasis.

\section{Tumor-induced lymphangiogenesis}

Some tumor types, including melanoma and cancers of the breast, lung and gastrointestinal tract, preferably spread via lymphatics [166]. Sentinel lymph node biopsy of patients with these tumors is routinely used for refinement of prognostic and therapeutic measures. Since the lymphatic vasculature is specialized for entry and transport of immune cells, lymphogenous spread is more efficient than that via blood vessels. Lymphatic capillaries are larger, lack a basal lamina and display an endothelial cell arrangement facilitating intravasation of cells. Moreover, the composition of lymph is similar to interstitial fluid and flow velocities are low, thus allowing better cell viability as compared with the serum toxicity and shear stress encountered in the bloodstream [167]. Histological analyses of human primary tumor samples demonstrate a consistent correlation between the presence of enlarged peri-tumoral lymphatics and the incidence of regional lymph node metastases $[168,169]$. Moreover, animal models clearly demonstrate a significant promotion of lymphogenic metastasis by tumor-induced lymphangiogenesis (reviewed in [170]). VEGF-C and $\mathrm{D}$ are the two most-investigated secreted lymphangiogenic factors. During secretion from the producing cell, these glycoproteins are proteolytically processed by plasmin and other (unknown) proteases. Unprocessed forms can only bind to VEGF receptor-3 (VEGFR-3), which is usually found on both normal and tumor lymphatic endothelial cells. Processing of VEGF-C and D increases the binding affinity for VEGFR-3 and allows binding to VEGFR-2, which is specifically expressed on blood vessel endothelial cells. Therefore, expression and the processing status of VEGF-C and D in a given tissue appear to determine the lymphangiogenic and angiogenic activities of these growth factors [171]. Expression of VEGF-C in tumor tissue serves as a reliable marker for ongoing tumor lymphangiogenesis and increased risk of regional lymph node metastasis in many cancer types $[172,173]$. Data for VEGF-D are less consistent suggesting that its ability to promote metastatic spread via lymphatics depends on the investigated cancer type and/ or grade [174-176].

The question remains whether VEGF-C and D may alter adhesive properties of both tumor and endothelial cells or modify functional features of lymphatic vessels, thus enhancing tumor cell adhesion to and intravasation into lymphatics. In addition, it is conceivable that VEGF-C and D activate lymphatic endothelial cells to secrete chemotactic factors for tumor cells. Although it is known that both tumor and stromal cells can express VEGF-C and $\mathrm{D}[53,177]$, it is not clear to what extent and upon which signals cells of the tumor stroma contribute to tumor-associated lymphangiogenesis [178]. Moreover, the genetic background of a given patient may modulate expression levels and processing of VEGF family members 
and thereby determine the biological behavior of a tumor $[179,180]$.

\section{Carcinoma-associated fibroblasts}

Besides endothelial cells of nearby vessels, neoplastic cells can also activate resident fibroblasts, which then cooperate in tumor progression (fig. 2). Activated fibroblasts or myofibroblasts (also called carcinoma-associated fibroblasts, CAFs) are often encountered at the invasive front of many different cancer types. Myofibroblasts share features of both smooth muscle cells and fibroblasts and are important promoters of growth and differentiation during embryogenesis, wound healing and other tissue-remodeling processes [181]. It is predominantly fibroblasts that transdifferentiate into myofibroblasts, but also vascular smooth muscle cells, pericytes, hematopoietic bone marrow-derived precursor cells and even cancer cells themselves are discussed as putative progenitors. Tumor cell-secreted platelet-derived growth factor (PDGF) stimulates fibroblast proliferation and the release of TGF- $\beta$ from macrophages, which itself is chemotactic for fibroblasts at lower concentrations and induces their transdifferentiation into myofibroblasts at high concentrations [181]. Furthermore, tumor cells often express TGF- $\beta$ themselves [121]. Myofibroblasts appear shortly before the invasive stage of tumors and promote degradation of basement membranes and ECM by secreting serine proteases, MMPs and urokinase plasminogen activator. Moreover, they express IGFs and HGF/SF, thus promoting cell-survival and migration, as well as the pro-angiogenic factors FGF-2 and VEGF and the pro-inflammatory cytokines IL-1, 6, 8 and TNF- $\alpha$. By doing so, myofibroblasts not only stimulate their own migration into the tumor, but also promote survival, proliferation and invasion of adjacent cancer cells as well as angiogenesis, collectively enhancing metastasis [182-184].

Fibroblasts of the tumor stroma participate in the decision whether neighboring tumor cells proliferate and invade into surrounding tissue and metastasize to distant sites [185]. For example, epithelial cells and fibroblasts in tissues that line portals of entry to the body secrete high levels of IFN $\beta$, whereas fibroblasts of internal organs do not. It has been demonstrated in xenotransplant and in vitro experiments that IFN $\beta$ secreted by skin fibroblasts downregulates expression of FGF-2 and secreted type IV collagenase in transplanted colon and renal carcinoma cells, thereby inhibiting their angiogenic and invasive capabilities in the skin. In contrast, when transplanted orthotopically, tumor cells express high levels of FGF-2 and secreted type IV collagenase, resulting in the development of highly vascularized and metastatic tumors $[186,187]$. Moreover, transgenic mice in which TGF- $\beta$ receptor type II is selectively inactivated in fi- broblasts develop prostate and gastric cancer even in the absence of mutations in the respective epithelial cells [188]. Notably, the mutated fibroblasts secrete high levels of HGF/SF, thereby conferring a paracrine tumorigenic signal on the epithelial cells.

\section{Contribution of the immune system to tumor metastasis}

The increased incidence of cancer in immunosuppressed patients and intense research in tumor immunology over the past years provide evidence that the immune system can to some degree recognize and eliminate tumor cells $[190,191]$. Nevertheless, an increasing body of evidence indicates that immune cells represent a double-edged sword during tumorigenesis. Although many tumors are potentially immunogenic, they evidently develop mechanisms to escape immunosurveillance by various mechanisms and can even 'educate' immune cells to support tumor cell survival and proliferation. Many recent reports have addressed these functions of the immune system and suggest new strategies how to therapeutically boost a cancer patient's immune response against the cancer. However, only limited insights have been gained into the role of immune cells during late-stage tumor progression and metastasis. Apparently, tumor-induced immunotolerance not only allows primary tumor outgrowth but also metastasis. Such 'immunological' involvement of the immune system in preventing carcinogenesis has been recently summarized [192]. Here, we restrict ourselves to the question of whether 'tumor-educated' immune cells can actively contribute to tumor cell migration, invasion and metastatic dissemination.

\section{The innate immune system}

The innate immune system recognizes and eliminates many exogenous infectious agents as well as altered host cells independent of preexisting specific (adaptive) immunity. Macrophages, dendritic cells (DCs) and natural killer cells (NKs) are cellular components of the innate immune system. Whereas macrophages have been repeatedly shown to promote tumor growth and metastasis by various mechanisms, NKs are usually associated with suppression of tumor metastasis, and DCs exert both antitumor and tumor immunosuppressive activities.

\section{Tumor-associated macrophages}

Macrophages are critical players in inflammation, wound healing, tissue repair and remodeling. Due to their antigen-presenting activity, they play a central role in cellbased immunity and can execute cells via cytotoxic mechanisms [193, 194]. Tumor cell damage and hypoxia are general attractants for circulating monocytes, and the presence of leukocytes in hypoxic areas of tumors is a well-known phenomenon [195-197]. In addition, neo- 
plastic cells, tumoral fibroblasts and smooth muscle cells produce distinct monocyte-attracting factors, including monocyte chemoattractant protein-1 (MCP-1), colonystimulating factor-1 (CSF-1), granulocyte-colony stimulating factor (G-CSF), VEGF-A, PIGF and VEGF-C [198-200]. Upon invasion into the tumor tissue, monocytes differentiate into macrophages and are specifically activated or de-activated, depending on the cytokine milieu encountered.

Consistent with their antigen-presenting and cytotoxic role in inflammation, high numbers of macrophages within or in the periphery of tumors (tumor-associated macrophages, TAMs) can repress tumor growth and progression [201, 202]. Surprisingly however, most clinical and experimental data correlate high TAM counts with reduced disease-free and overall survival. This discrepancy has been explained by a tumor type-specific paracrine cytokine crosstalk between tumor cells and TAMs: tumors secreting granulocyte-monocyte colony stimulating factor (GM-CSF), IFN $\gamma$ and IL-12 promote the antigen-presenting and cytotoxic activities of macrophages (reviewed in [198, 203, 204]). In contrast, most tumor cells secrete VEGF-A, TGF- $\beta$, IL-6, CSF- 1 and low-dose TNF $\alpha$, all factors that inhibit the TAMs' antigen-presenting activities and rather support immunosuppression, angiogenesis, tumor cell proliferation and invasion [205208]. In turn, these TAMs promote tumor cell proliferation by secreting a variety of tumor promoting factors, including nitric oxide (NO), EGF, FGF-8b, HGF/SF, IGF-I, TGF- $\beta$, VEGF-C and PDGF. Alternatively, activated macrophages can stimulate tumor cells to secrete these factors in an autocrine fashion [209-214]. Furthermore, TAMs themselves potently stimulate tumor angiogenesis and lymphangiogenesis by secreting growth factors, cytokines and chemokines [215-217]. Interestingly, in a cornea model of inflammation-induced lymphangiogenesis, macrophages transdifferentiate and directly incorporate into the endothelial layer of nascent lymphatic vessels [217]. By releasing MMPs, plasminogen activators, hyaluronidase and other enzymes involved in the breakdown of the ECM, TAMs liberate matrix-bound angiogenic molecules, including VEGF-A and IL- $1 \beta$, thus further enhancing angiogenesis and tumor cell migration and invasion (fig. 2) [203, 218, 219]. Notably, TAMs have also been found to actively associate with tumor cells via adhesion molecules, such as ICAM-1 and sialoadhesin, and to convey them into efferent blood vessels [220]. Since macrophage activity is associated with the release of reactive oxygen and other mutagenic compounds, they might also indirectly induce additional genetic pro-tumorigenic and pro-metastatic alterations [3, 4, 221].

\section{$N K s$ and DCs}

NKs are a derivative of the CD8+ T-lymphocyte lineage, but lack the rearrangement of T-cell receptor genes. NKT cells represent a subtype sharing characteristics with NK and T cells. It is well-established that NKs and NKTs display important anti-tumor activity by inducing death of tumor cells through direct contact or by the secretion of pro-apoptotic cytokines [222, 223]. In parallel, NKs stimulate the maturation of DCs, which are first-line antigenpresenting cells, and thereby promote specific anti-tumor immunity mediated by cytotoxic CD8+ T lymphocytes (CTLs) and B lymphocytes [224]. In cancer patients, high peripheral blood NK activity significantly correlates with longer metastasis-free survival [225]. Experiments using perforin-deficient mice clearly demonstrate that NK-mediated cytotoxicity is one of the essential anti-metastatic mechanisms performed by the innate immune system [226-228]. Further details on NK-mediated tumor surveillance and anti-metastatic activity have been recently summarized [229]. To date, here is no evidence indicating a potential pro-metastatic role of NKs.

DCs are classical antigen-presenting cells, which can initiate strong CTL-mediated anti-tumor immune responses. They are generally divided into myeloid and plasmacytoid DCs with differences in cell-surface receptors, anatomic localization and function [192]. Recently, a third type of DCs, vascular DCs (VDCs), was identified, which simultaneously expresses endothelial and DC markers. Strikingly, VDCs can assemble into functional blood vessels [230]. Depending on the cytokine milieu encountered in tumors, DCs can either mediate anti-tumor activity or support tumor growth and metastasis. In fact, increasing evidence from analyses of human ovarian, breast, prostate and renal cell carcinoma reveals the presence of tumor-promoting rather than tumor-suppressing dendritic cells, and altered dendritic cell function and differentiation is likely to be one of the most fundamental mechanisms by which tumors escape immune responses [231-235]. Pro-tumorigenic dendritic cells can favor metastasis by inducing tumor immunotolerance and by promoting tumor angiogenesis. Whereas mature myeloid DCs act as classical antigenpresenting cells, immature or partially differentiated myeloid DCs can tolerize $\mathrm{T}$ cells to self-antigens by inducing either suppressive $\mathrm{T}$ cells or T-cell unresponsiveness. This mechanism of immunomodulation is particularly important to counteract autoimmune reactions, but can be abused by tumors as well [236, 237]. Tumor cells, TAMs and tumoral immunosuppressive $\mathrm{T}$ cells can secrete high amounts of VEGF-A, IL-6, macrophage colony-stimulating factor (M-CSF), COX2, IL-10, TGF$\beta$ and gangliosides, which suppress maturation of DCs [192]. Most myeloid DCs found in human ovarian, breast, prostate and renal cell carcinoma are therefore immature and may induce tumor immunotolerance [231-234]. Tumor-secreted IL-10 and VEGF also induce expression of B7-H1 on myeloid dendritic cells, a ligand for PD-1 receptor expressed on suppressor T cells [238]. A study 
published this year demonstrates that the metastatic ability of melanoma and colon cancer cells expressing B7$\mathrm{H} 1$ is abolished in PD-1-deficient mice and that tumors also grow more slowly [239]. These and other experiments indirectly show that tumor cell escape from immunosurveillance - in this case mediated by modulation of myeloid DC and suppressive T cell function - is essential for tumor growth and metastasis.

The involvement of dendritic cells in tumor angiogenesis has recently drawn major attention. It is thought that mature myeloid DCs suppress tumor angiogenesis and thereby impede both tumor growth and metastasis by secreting or stimulating the production of anti-angiogenic factors, such as IL-12, IFN $\gamma$ and IL-10 [240]. Conversely, the tumor-induced suppression of myeloid DC maturation described above therefore enhances tumor angiogenesis. Moreover, tumors contain significant numbers of plasmacytoid and vascular DCs secreting pro-angiogenic molecules, such as TNF $\alpha$ and IL-8 [230, 240, 241]. Based on this rather complex situation, the involvement of DCs in tumor angiogenesis and metastasis and their therapeutic exploitation certainly deserves future investigation.

\section{The adaptive immune system and metastasis}

After a primary contact with an antigen, the adaptive immune system confers longterm antigen-specific immunological memory. Its basic mediators are $\mathrm{T}$ and $\mathrm{B}$ lymphocytes. CD8+ cytotoxic T cells (CTLs) together with NKs are the fundamental effectors of immune response-mediated tumor cell elimination via the release of cytokines that activate death receptors on the tumor cell surface. CD4+ Thelper cells are central to the development of immune responses by activating antigen-specific effector cells and recruiting cells of the innate immune system [242, 243]. As mentioned earlier, suppressor T cells play an important role in inducing tumor immunotolerance, which might not only allow tumor growth but also metastasis [237, 244]. Nevertheless, stimulation of anti-tumor $T$ cell response has been shown to be a promising strategy to counteract tumor growth and metastasis in mouse tumor models and in human cancer [245-247].

B lymphocytes are antigen-presenting cells which can differentiate into antibody-producing plasma cells. Thereby they can stimulate both cytotoxic and humoral antitumor immune responses. On the other hand, there is mounting evidence that B cells can also promote tumor cell invasiveness and metastasis. In one study, tumor cells producing antigenic Secreted/shed Tumor GlycoProteins (STGPs) were transplanted into immune-competent mice or mice deficient in T cells [248]. In both mouse lines, increased tumor cell invasion correlated with an increase in serum anti-STPG IgG levels and tumoral infiltration of cells of the innate and adaptive immune system. Experimental infiltration of specific anti-
STGP-IgG-secreting plasmocytoma cells further promoted tumor invasion, angiogenesis and metastasis. Apparently, the humoral anti-STGP response stimulated the tumor infiltrating stromal cells to release proinflammatory cytokines and VEGF, thereby promoting invasion and metastasis.

Recent work with a transgenic mouse model of multistage skin carcinogenesis (K14-HPV16) demonstrated a similar surprising pro-tumorigenic role of $\mathrm{B}$ but not $\mathrm{T}$ lymphocytes in the development of inflammation-associated de novo epithelial cancer. Upon crossing K14HPV16 mice with $\mathrm{T}$ and B lymphocyte-deficient $\mathrm{RAG}^{-/-}$ mice resulted in reduced tumor progression [249]. Conversely, adoptive transfer of B lymphocytes or serum from K14-HPV16 mice restored the infiltration of innate immune cells into premalignant tissue and the progression to malignancy. These studies indicate that B cells and even antibodies produced by B cells contribute to tumor progression and metastasis. Of course, these surprising results raise an important caveat for the application of vaccination-based cancer therapies that aim to stimulate B cell responses in patients with pre-malignant disease.

\section{Conclusions}

Apparently, cancer needs to be treated at an early tumor stage or grade in order to prevent the formation of metastases. Nevertheless, even when cancer may have already spread throughout the body, targeting the growth of primary and secondary tumors as well as further tumor cell spread may significantly improve quality of life and overall survival of patients. Although 'curing cancer' may be an unrealistic notion in advanced-stage tumors, a significant fraction of patients may nevertheless profit from a cocktail of drugs inhibiting tumor progression at different levels. Most of the experimental results presented here highlight many pathways and mechanisms that may be appropriate targets for the development of such therapeutic interventions. Prevention of further metastatic dissemination, in addition to the reduction of tumor load, is certainly a prerequisite to convert a rapidly fatal disease into a chronic illness.

Acknowledgements. The authors are grateful to Dr. Miguel Cabrita and Dr. Tibor Schomber for critically reading the manuscript. We apologize to all colleagues whose important work we could not cite due to space limitations. Research in the laboratory of the authors is supported by the Swiss National Science Foundation, Swiss Bridge Award, Krebsliga Beider Basel, EU-FP6 framework programmes LYMPHANGIOGENOMICS LSHG-CT-2004-503573 and BRECOSM LSHC-CT-2004-503224, and Novartis Pharma Inc.

1 Chambers A. F., Groom A. C. and MacDonald I. C. (2002) Dissemination and growth of cancer cells in metastatic sites. Nat. Rev. Cancer 2: 563-572 
2 Crissman J. D. (1986) Tumor-host interactions as prognostic factors in the histologic assessment of carcinomas. Pathol. Annu. 21 Pt 1: 29-52

3 Pollard J. W. (2004) Tumour-educated macrophages promote tumour progression and metastasis. Nat. Rev. Cancer 4: 71-78

4 Mueller M. M. and Fusenig N. E. (2004) Friends or foes bipolar effects of the tumour stroma in cancer. Nat. Rev. Cancer 4: 839-849

5 Cavallaro U. and Christofori G. (2004) Cell adhesion and signalling by cadherins and Ig-CAMs in cancer. Nat. Rev. Cancer 4: $118-132$

6 Kobielak A. and Fuchs E. (2004) Alpha-catenin: at the junction of intercellular adhesion and actin dynamics. Nat. Rev. Mol. Cell. Biol. 5: 614-625

7 Hirohashi S. (1998) Inactivation of the E-cadherin-mediated cell adhesion system in human cancers. Am. J. Pathol. 153: 333-339

8 Perl A. K., Wilgenbus P., Dahl U., Semb H. and Christofori G. (1998) A causal role for E-cadherin in the transition from adenoma to carcinoma. Nature 392: 190-193

9 Grunert S., Jechlinger M. and Beug H. (2003) Diverse cellular and molecular mechanisms contribute to epithelial plasticity and metastasis. Nat. Rev. Mol. Cell. Biol. 4: 657-665

10 Tarin D., Thompson E. W. and Newgreen D. F. (2005) The fallacy of epithelial mesenchymal transition in neoplasia. Cancer Res. 65: 5996-6000; discussion 6000-5991

11 Thiery J. P. (2002) Epithelial-mesenchymal transitions in tumour progression. Nat. Rev. Cancer 2: $442-454$

12 Janda E., Lehmann K., Killisch I., Jechlinger M., Herzig M., Downward J. et al. (2002) Ras and TGF[beta] cooperatively regulate epithelial cell plasticity and metastasis: dissection of Ras signaling pathways. J. Cell. Biol. 156: 299-313

13 Peinado H., Portillo F. and Cano A. (2004) Transcriptional regulation of cadherins during development and carcinogenesis. Int. J. Dev. Biol. 48: 365-375

14 Barrallo-Gimeno A. and Nieto M. A. (2005) The Snail genes as inducers of cell movement and survival: implications in development and cancer. Development 132: 3151-3161

15 Sugimachi K., Tanaka S., Kameyama T., Taguchi K., Aishima S., Shimada M. et al. (2003) Transcriptional repressor snail and progression of human hepatocellular carcinoma. Clin. Cancer Res. 9: 2657-2664

16 Blanco M. J., Moreno-Bueno G., Sarrio D., Locascio A., Cano A., Palacios J. et al. (2002) Correlation of Snail expression with histological grade and lymph node status in breast carcinomas. Oncogene 21: 3241-3246

17 Yook J. I., Li X. Y., Ota I., Fearon E. R. and Weiss S. J. (2005) Wnt-dependent regulation of the E-cadherin repressor snail. J Biol Chem. 180: 11746-11748

18 Kang Y. and Massague J. (2004) Epithelial-mesenchymal transitions: twist in development and metastasis. Cell 118: $277-$ 279

19 Lu Z., Ghosh S., Wang Z. and Hunter T. (2003) Downregulation of caveolin-1 function by EGF leads to the loss of E-cadherin, increased transcriptional activity of beta-catenin, and enhanced tumor cell invasion. Cancer Cell 4: 499-515

20 Zhou B. P., Deng J., Xia W., Xu J., Li Y. M., Gunduz M. et al. (2004) Dual regulation of Snail by GSK-3beta-mediated phosphorylation in control of epithelial-mesenchymal transition. Nat. Cell Biol. 6: 931-940

21 Strathdee G. (2002) Epigenetic versus genetic alterations in the inactivation of E-cadherin. Semin. Cancer Biol. 12: 373-379

22 Kamei T., Matozaki T., Sakisaka T., Kodama A., Yokoyama S., Peng Y. F. et al. (1999) Coendocytosis of cadherin and c-Met coupled to disruption of cell-cell adhesion in MDCK cells regulation by Rho, Rac and Rab small G proteins. Oncogene 18: $6776-6784$

23 Morali O. G., Delmas V., Moore R., Jeanney C., Thiery J. P. and Larue L. (2001) IGF-II induces rapid beta-catenin reloca- tion to the nucleus during epithelium to mesenchyme transition. Oncogene 20: 4942-4950

24 Behrens J., Vakaet L., Friis R., Winterhager E., Van Roy F., Mareel M. M. et al. (1993) Loss of epithelial differentiation and gain of invasiveness correlates with tyrosine phosphorylation of the E-cadherin/beta-catenin complex in cells transformed with a temperature-sensitive v-SRC gene. J. Cell. Biol. 120: 757-766

25 Fujita Y., Krause G., Scheffner M., Zechner D., Leddy H. E., Behrens J. et al. (2002) Hakai, a c-Cbl-like protein, ubiquitinates and induces endocytosis of the E-cadherin complex. Nat. Cell Biol. 4: 222-231

26 McCawley L. J., O'Brien P. and Hudson L. G. (1998) Epidermal growth factor (EGF)- and scatter factor/hepatocyte growth factor (SF/HGF)- mediated keratinocyte migration is coincident with induction of matrix metalloproteinase (MMP)-9. J. Cell Physiol. 176: 255-265

27 Sahai E. and Marshall C. J. (2002) RHO-GTPases and cancer Nat. Rev. Cancer 2: 133-142

28 Noren N. K., Arthur W. T. and Burridge K. (2003) Cadherin engagement inhibits RhoA via p190RhoGAP. J. Biol. Chem. 278: $13615-13618$

29 Kuroda S., Fukata M., Nakagawa M., Fujii K., Nakamura T., Ookubo T. et al. (1998) Role of IQGAP1, a target of the small GTPases Cdc42 and Rac1, in regulation of E-cadherin- mediated cell-cell adhesion. Science 281: 832-835

30 Noren N. K., Niessen C. M., Gumbiner B. M. and Burridge K. (2001) Cadherin engagement regulates Rho family GTPases. J. Biol. Chem. 276: 33305-33308

31 Itoh K., Yoshioka K., Akedo H., Uehata M., Ishizaki T. and Narumiya S. (1999) An essential part for Rho-associated kinase in the transcellular invasion of tumor cells. Nat. Med. 5: 221-225

32 Clark E. A., Golub T. R., Lander E. S. and Hynes R. O. (2000) Genomic analysis of metastasis reveals an essential role for RhoC. Nature 406: 532-535

33 Sander E. E., van Delft S., ten Klooster J. P., Reid T., van der Kammen R. A., Michiels F. et al. (1998) Matrix-dependent Tiam1/Rac signaling in epithelial cells promotes either cellcell adhesion or cell migration and is regulated by phosphatidylinositol 3-kinase. J. Cell. Biol. 143: 1385-1398

34 Cavallaro U., Niedermeyer J., Fuxa M. and Christofori G. (2001) N-CAM modulates tumour-cell adhesion to matrix by inducing FGF-receptor signalling. Nat. Cell Biol. 3: 650-657

35 Suyama K., Shapiro I., Guttman M. and Hazan R. B. (2002) A signaling pathway leading to metastasis is controlled by $\mathrm{N}$ cadherin and the FGF receptor. Cancer Cell 2: 301-314

36 Guo W. and Giancotti F. G. (2004) Integrin signalling during tumour progression. Nat. Rev. Mol. Cell. Biol. 5: 816-826

37 Hood J. D. and Cheresh D. A. (2002) Role of integrins in cell invasion and migration. Nat. Rev. Cancer 2: 91-100

38 Hynes R. O. (2002) Integrins: bidirectional, allosteric signaling machines. Cell 110: 673-687

39 Friedl P. and Wolf K. (2003) Tumour-cell invasion and migration: diversity and escape mechanisms. Nat. Rev. Cancer 3: 362-374

40 Bissell M. J. and Radisky D. (2001) Putting tumours in context. Nat. Rev. Cancer 1: 46-54

41 Natali P. G., Hamby C. V., Felding-Habermann B., Liang B., Nicotra M. R., Di Filippo F. et al. (1997) Clinical significance of alpha(v)beta3 integrin and intercellular adhesion molecule1 expression in cutaneous malignant melanoma lesions. Cancer Res. 57: 1554-1560

42 Gingras M. C., Roussel E., Bruner J. M., Branch C. D. and Moser R. P. (1995) Comparison of cell adhesion molecule expression between glioblastoma multiforme and autologous normal brain tissue. J. Neuroimmunol. 57: 143-153

43 Rolli M., Fransvea E., Pilch J., Saven A. and Felding-Habermann B. (2003) Activated integrin alphavbeta3 cooperates 
with metalloproteinase MMP-9 in regulating migration of metastatic breast cancer cells. Proc. Natl. Acad. Sci USA 100: 9482-9487

44 Rabinovitz I. and Mercurio A. M. (1997) The integrin $\alpha 6 \beta 4$ functions in carcinoma cell migration on laminin-1 by mediating the formation and stabilization of actin-containing motility structures. J. Cell. Biol. 139: 1873-1884

45 Maaser K., Wolf K., Klein C. E., Niggemann B., Zanker K. S., Brocker E. B. et al. (1999) Functional hierarchy of simultaneously expressed adhesion receptors: integrin alpha2beta1 but not CD44 mediates MV3 melanoma cell migration and matrix reorganization within three-dimensional hyaluronan-containing collagen matrices. Mol. Biol. Cell 10: 3067-3079

46 Ballestrem C., Hinz B., Imhof B. A. and Wehrle-Haller B. (2001) Marching at the front and dragging behind: differential alphaVbeta3-integrin turnover regulates focal adhesion behavior. J. Cell. Biol. 155: 1319-1332

47 Senger D. R., Perruzzi C. A., Streit M., Koteliansky V. E., de Fougerolles A. R. and Detmar M. (2002) The alpha(1)beta(1) and alpha(2)beta(1) integrins provide critical support for vascular endothelial growth factor signaling, endothelial cell migration and tumor angiogenesis. Am. J. Pathol. 160: 195204

48 Reynolds L. E., Wyder L., Lively J. C., Taverna D., Robinson S. D., Huang X. et al. (2002) Enhanced pathological angiogenesis in mice lacking beta 3 integrin or beta 3 and beta5 integrins. Nat. Med. 8: 27-34

49 Silletti S., Yebra M., Perez B., Cirulli V., McMahon M. and Montgomery A. M. (2004) Extracellular signal-regulated kinase (ERK)-dependent gene expression contributes to L1 cell adhesion molecule-dependent motility and invasion. J. Biol. Chem. 279: 28880-28888

50 Roesler J., Srivatsan E., Moatamed F., Peters J. and Livingston E. H. (1997) Tumor suppressor activity of neural cell adhesion molecule in colon carcinoma. Am. J. Surg. 174: 251-257

51 Tezel E., Kawase Y., Takeda S., Oshima K. and Nakao A. (2001) Expression of neural cell adhesion molecule in pancreatic cancer. Pancreas 22: 122-125

52 Perl A. K., Dahl U., Wilgenbus P., Cremer H., Semb H. and Christofori G. (1999) Reduced expression of neural cell adhesion molecule induces metastatic dissemination of pancreatic beta tumor cells. Nat. Med. 5: 286-291

53 Crnic I., Strittmatter K., Cavallaro U., Kopfstein L., Jussila L., Alitalo K. et al. (2004) Loss of neural cell adhesion molecule induces tumor metastasis by up-regulating lymphangiogenesis. Cancer Res. 64: 8630-8638

54 Izumi Y., Hirata M., Hasuwa H., Iwamoto R., Umata T., Miyado K. et al. (1998) A metalloprotease-disintegrin, MDC9/meltrin-gamma/ADAM9 and PKCdelta are involved in TPA-induced ectodomain shedding of membrane-anchored heparin-binding EGF-like growth factor. EMBO J. 17: 72607272

55 Thies A., Schachner M., Moll I., Berger J., Schulze H. J., Brunner G. et al. (2002) Overexpression of the cell adhesion molecule L1 is associated with metastasis in cutaneous malignant melanoma. Eur. J. Cancer 38: 1708-1716

56 Calvo A., Xiao N., Kang J., Best C. J., Leiva I., Emmert-Buck M. R. et al. (2002) Alterations in gene expression profiles during prostate cancer progression: functional correlations to tumorigenicity and downregulation of selenoprotein-P in mouse and human tumors. Cancer Res. 62: 5325-5335

57 Katayama M., Iwamatsu A., Masutani H., Furuke K., Takeda K., Wada H. et al. (1997) Expression of neural cell adhesion molecule L1 in human lung cancer cell lines. Cell Struct. Funct. 22: $511-516$

58 Heiz M., Grunberg J., Schubiger P. A. and Novak-Hofer I. (2004) Hepatocyte growth factor-induced ectodomain shedding of cell adhesion molecule L1: role of the L1 cytoplasmic domain. J. Biol. Chem. 279: 31149-31156
59 Fogel M., Huszar M., Altevogt P. and Ben-Arie A. (2004) L1 (CD171) as a novel biomarker for ovarian and endometrial carcinomas. Expert Rev. Mol. Diagn. 4: 455-462

60 Mechtersheimer S., Gutwein P., Agmon-Levin N., Stoeck A., Oleszewski M., Riedle S. et al. (2001) Ectodomain shedding of L1 adhesion molecule promotes cell migration by autocrine binding to integrins. J. Cell. Biol. 155: 661-673

61 Thelen K., Kedar V., Panicker A. K., Schmid R. S., Midkiff B. R. and Maness P. F. (2002) The neural cell adhesion molecule L1 potentiates integrin-dependent cell migration to extracellular matrix proteins. J. Neurosci. 22: 4918-4931

62 Gutwein P., Stoeck A., Riedle S., Gast D., Runz S., Condon T. P. et al. (2005) Cleavage of L1 in exosomes and apoptotic membrane vesicles released from ovarian carcinoma cells. Clin. Cancer Res. 11: 2492-2501

63 Gast D., Riedle S., Schabath H., Schlich S., Schneider A., Issa Y. et al. (2005) L1 augments cell migration and tumor growth but not beta3 integrin expression in ovarian carcinomas. Int. J. Cancer 115: 658-665

64 Gavert N., Conacci-Sorrell M., Gast D., Schneider A., Altevogt P., Brabletz T. et al. (2005) L1, a novel target of betacatenin signaling, transforms cells and is expressed at the invasive front of colon cancers. J. Cell. Biol. 168: 633-642

65 Blume-Jensen P. and Hunter T. (2001) Oncogenic kinase signalling. Nature 411: 355-365

66 Maulik G., Shrikhande A., Kijima T., Ma P. C., Morrison P. T. and Salgia R. (2002) Role of the hepatocyte growth factor receptor, c-Met, in oncogenesis and potential for therapeutic inhibition. Cytokine Growth Factor Rev. 13: 41-59

67 Rong S., Segal S., Anver M., Resau J. H., Vande Woude G. F. (1994) Invasiveness and metastasis of NIH 3T3 cells induced by Met-hepatocyte growth factor/scatter factor autocrine stimulation. Proc. Natl. Acad. Sci USA 91: 4731-4735

68 Takayama H., LaRochelle W. J., Sharp R., Otsuka T., Kriebel P., Anver M. et al. (1997) Diverse tumorigenesis associated with aberrant development in mice overexpressing hepatocyte growth factor/scatter factor. Proc. Natl. Acad. Sci USA 94: 701-706

69 Birchmeier C., Birchmeier W., Gherardi E., Vande Woude G. F. (2003) Met, metastasis, motility and more. Nat. Rev. Mol. Cell. Biol. 4: 915-925

70 Peschard P., Fournier T. M., Lamorte L., Naujokas M. A., Band H., Langdon W. Y. et al. (2001) Mutation of the c-Cbl $\mathrm{TKB}$ domain binding site on the Met receptor tyrosine kinase converts it into a transforming protein. Mol. Cell 8: 9951004

71 Giordano S., Bardelli A., Zhen Z., Menard S., Ponzetto C. and Comoglio P. M. (1997) A point mutation in the MET oncogene abrogates metastasis without affecting transformation. Proc. Natl. Acad. Sci USA 94: 13868-13872

72 Khwaja A., Lehmann K., Marte B. M. and Downward J. (1998) Phosphoinositide 3-kinase induces scattering and tubulogenesis in epithelial cells through a novel pathway. J. Biol. Chem. 273: 18793-18801

73 Bardelli A., Basile M. L., Audero E., Giordano S., Wennstrom S., Menard S. et al. (1999) Concomitant activation of pathways downstream of Grb2 and PI 3-kinase is required for MET-mediated metastasis. Oncogene 18: 1139-1146

74 Paumelle R., Tulasne D., Kherrouche Z., Plaza S., Leroy C., Reveneau S. et al. (2002) Hepatocyte growth factor/scatter factor activates the ETS1 transcription factor by a RAS-RAFMEK-ERK signaling pathway. Oncogene 21: 2309-2319

75 Yu Y., Zhang Y. C., Zhang W. Z., Shen L. S., Hertzog P., Wilson T. J. et al. (2003) Ets1 as a marker of malignant potential in gastric carcinoma. World J. Gastroenterol. 9: 21542159

76 Takai N., Miyazaki T., Fujisawa K., Nasu K. and Miyakawa I. (2000) Expression of c-Ets1 is associated with malignant potential in endometrial carcinoma. Cancer 89: 2059-2067 
77 Trusolino L., Bertotti A. and Comoglio P. M. (2001) A signaling adapter function for alpha6beta4 integrin in the control of HGF-dependent invasive growth. Cell 107: 643-654

78 Isacke C. M. and Yarwood H. (2002) The hyaluronan receptor, CD44. Int. J. Biochem. Cell Biol. 34: 718-721

79 Orian-Rousseau V., Chen L., Sleeman J. P., Herrlich P. and Ponta H. (2002) CD44 is required for two consecutive steps in HGF/c-Met signaling. Genes Dev. 16: 3074-3086

80 Guba M., von Breitenbuch P., Steinbauer M., Koehl G., Flegel S., Hornung M. et al. (2002) Rapamycin inhibits primary and metastatic tumor growth by antiangiogenesis: involvement of vascular endothelial growth factor. Nat. Med. 8: 128-135

81 Harrison G. M., Davies G., Martin T. A., Jiang W. G. and Mason M. D. (2002) Distribution and expression of CD44 isoforms and Ezrin during prostate cancer-endothelium interaction. Int. J. Oncol. 21: 935-940

82 Crepaldi T., Gautreau A., Comoglio P. M., Louvard D. and Arpin M. (1997) Ezrin is an effector of hepatocyte growth factor-mediated migration and morphogenesis in epithelial cells. J. Cell. Biol. 138: 423-434

83 Medico E., Gentile A., Lo Celso C., Williams T. A., Gambarotta G., Trusolino L. et al. (2001) Osteopontin is an autocrine mediator of hepatocyte growth factor-induced invasive growth. Cancer Res. 61: 5861-5868

84 Zohar R., Suzuki N., Suzuki K., Arora P., Glogauer M., McCulloch C. A. et al. (2000) Intracellular osteopontin is an integral component of the CD44-ERM complex involved in cell migration. J. Cell Physiol. 184: 118-130

85 Tuck A. B., Arsenault D. M., O’Malley F. P., Hota C., Ling M. C., Wilson S. M. et al. (1999) Osteopontin induces increased invasiveness and plasminogen activator expression of human mammary epithelial cells. Oncogene 18: 4237-4246

86 Barton W. A., Himanen J. P., Antipenko A. and Nikolov D. B. (2004) Structures of axon guidance molecules and their neuronal receptors. Adv. Protein Chem. 68: 65-106

87 Conrotto P., Corso S., Gamberini S., Comoglio P. M. and Giordano S. (2004) Interplay between scatter factor receptors and B plexins controls invasive growth. Oncogene 23: 5131-5137

88 Giordano S., Corso S., Conrotto P., Artigiani S., Gilestro G., Barberis D. et al. (2002) The semaphorin 4D receptor controls invasive growth by coupling with Met. Nat. Cell Biol. 4: 720 724

89 Conrotto P., Valdembri D., Corso S., Serini G., Tamagnone L., Comoglio P. M. et al. (2005) Sema4D induces angiogenesis through Met recruitment by Plexin B1. Blood 105: 4321-4329

90 Ried S., Jager C., Jeffers M., Vande Woude G. F., Graeff H., Schmitt M. et al. (1999) Activation mechanisms of the urokinase-type plasminogen activator promoter by hepatocyte growth factor/scatter factor. J. Biol. Chem. 274: 1637716386

91 Ma P. C., Maulik G., Christensen J. and Salgia R. (2003) cMet: structure, functions and potential for therapeutic inhibition. Cancer Metastasis Rev. 22: 309-325

92 Reya T. and Clevers H. (2005) Wnt signalling in stem cells and cancer. Nature 434: 843-850

93 Giles R. H., van Es J. H. and Clevers H. (2003) Caught up in a Wnt storm: Wnt signaling in cancer. Biochim. Biophys. Acta 1653: $1-24$

94 Fodde R., Smits R. and Clevers H. (2001) APC, signal transduction and genetic instability in colorectal cancer. Nat. Rev. Cancer 1: 55-67

95 Gottardi C. J., Wong E. and Gumbiner B. M. (2001) E-cadherin suppresses cellular transformation by inhibiting betacatenin signaling in an adhesion-independent manner. J. Cell. Biol. 153: 1049-1060

96 Stockinger A., Eger A., Wolf J., Beug H. and Foisner R. (2001) E-cadherin regulates cell growth by modulating proliferationdependent beta-catenin transcriptional activity. J. Cell. Biol. 154: $1185-1196$
97 Wong A. S. and Gumbiner B. M. (2003) Adhesion-independent mechanism for suppression of tumor cell invasion by Ecadherin. J. Cell. Biol. 161: 1191-1203

98 Gottardi C. J. and Gumbiner B. M. (2004) Distinct molecular forms of beta-catenin are targeted to adhesive or transcriptional complexes. J. Cell. Biol. 167: 339-349

99 Jamora C., DasGupta R., Kocieniewski P. and Fuchs E. (2003) Links between signal transduction, transcription and adhesion in epithelial bud development. Nature 422: 317-322

100 Guaita S., Puig I., Franci C., Garrido M., Dominguez D., Batlle E. et al. (2002) Snail induction of epithelial to mesenchymal transition in tumor cells is accompanied by MUC1 repression and ZEB1 expression. J. Biol. Chem. 277: 39209-39216

101 Mosesson Y. and Yarden Y. (2004) Oncogenic growth factor receptors: implications for signal transduction therapy. Semin. Cancer Biol. 14: 262-270

102 Schroeder J. A., Adriance M. C., McConnell E. J., Thompson M. C., Pockaj B. and Gendler S. J. (2002) ErbB-beta-catenin complexes are associated with human infiltrating ductal breast and murine mammary tumor virus (MMTV)-Wnt-1 and MMTV-c-Neu transgenic carcinomas. J. Biol. Chem. 277: 22692-22698

103 Nelson W. J. and Nusse R. (2004) Convergence of Wnt, betacatenin and cadherin pathways. Science 303: 1483-1487

104 Baserga R. (1999) The IGF-I receptor in cancer research. Exp. Cell Res. 253: $1-6$

105 Jiang Y., Wang L., Gong W., Wei D., Le X., Yao J. et al. (2004) A high expression level of insulin-like growth factor I receptor is associated with increased expression of transcription factor $\mathrm{Sp} 1$ and regional lymph node metastasis of human gastric cancer. Clin. Exp. Metastasis 21: 755-764

106 Furukawa M., Raffeld M., Mateo C., Sakamoto A., Moody T. W., Ito T. et al. (2005) Increased expression of insulin-like growth factor I and/or its receptor in gastrinomas is associated with low curability, increased growth and development of metastases. Clin. Cancer Res. 11: 3233-3242

107 Prakash S., Sarran L., Socci N., DeMatteo R. P., Eisenstat J., Greco A. M. et al. (2005) Gastrointestinal stromal tumors in children and young adults: a clinicopathologic, molecular and genomic study of 15 cases and review of the literature. J. Pediatr. Hematol. Oncol. 27: 179-187

108 Gydee H., O’Neill J. T., Patel A., Bauer A. J., Tuttle R. M. and Francis G. L. (2004) Differentiated thyroid carcinomas from children and adolescents express IGF-I and the IGF-I receptor (IGF-I-R). Cancers with the most intense IGF-I-R expression may be more aggressive. Pediatr. Res. 55: 709-715

109 Lopez T. and Hanahan D. (2002) Elevated levels of IGF-1 receptor convey invasive and metastatic capability in a mouse model of pancreatic islet tumorigenesis. Cancer Cell 1: 339 353

110 Garcia-Echeverria C., Pearson M. A., Marti A., Meyer T., Mestan J., Zimmermann J. et al. (2004) In vivo antitumor activity of NVP-AEW541-A novel, potent and selective inhibitor of the IGF-IR kinase. Cancer Cell 5: 231-239

111 Mitsiades C. S., Mitsiades N. S., McMullan C. J., Poulaki V., Shringarpure R., Akiyama M. et al. (2004) Inhibition of the insulin-like growth factor receptor-1 tyrosine kinase activity as a therapeutic strategy for multiple myeloma, other hematologic malignancies and solid tumors. Cancer Cell 5: 221-230

112 Guvakova M. A. and Surmacz E. (1999) The activated insulinlike growth factor I receptor induces depolarization in breast epithelial cells characterized by actin filament disassembly and tyrosine dephosphorylation of FAK, Cas and paxillin. Exp. Cell Res. 251: 244-255

113 Hermanto U., Zong C. S., Li W. and Wang L. H. (2002) RACK1, an insulin-like growth factor I (IGF-I) receptor-interacting protein, modulates IGF-I-dependent integrin signaling and promotes cell spreading and contact with extracellular matrix. Mol. Cell Biol 22: 2345-2365 
114 Mauro L., Salerno M., Morelli C., Boterberg T., Bracke M. E. and Surmacz E. (2003) Role of the IGF-I receptor in the regulation of cell-cell adhesion: implications in cancer development and progression. J. Cell Physiol. 194: 108-116

115 Morali O. G., Jouneau A., McLaughlin K. J., Thiery J. P. and Larue L. (2000) IGF-II promotes mesoderm formation. Dev. Biol. 227: 133-145

116 Derynck R. and Zhang Y. E. (2003) Smad-dependent and Smad-independent pathways in TGF-beta family signalling. Nature 425: $577-584$

117 Attisano L. and Wrana J. L. (2002) Signal transduction by the TGF-beta superfamily. Science 296: 1646-1647

118 Watanabe H., de Caestecker M. P. and Yamada Y. (2001) Transcriptional cross-talk between Smad, ERK1/2 and p38 mitogen-activated protein kinase pathways regulates transforming growth factor-beta-induced aggrecan gene expression in chondrogenic ATDC5 cells. J. Biol. Chem. 276: 14466-14473

119 Bakin A. V., Tomlinson A. K., Bhowmick N. A., Moses H. L. and Arteaga C. L. (2000) Phosphatidylinositol 3-kinase function is required for transforming growth factor beta-mediated epithelial to mesenchymal transition and cell migration. J. Biol. Chem. 275: 36803-36810

120 Hay E., Lemonnier J., Fromigue O. and Marie P. J. (2001) Bone morphogenetic protein-2 promotes osteoblast apoptosis through a Smad-independent, protein kinase C-dependent signaling pathway. J. Biol. Chem. 276: 29028-29036

121 Siegel P. M. and Massague J. (2003) Cytostatic and apoptotic actions of TGF-beta in homeostasis and cancer. Nat. Rev. Cancer 3: 807-821

122 Derynck R., Akhurst R. J. and Balmain A. (2001) TGF-beta signaling in tumor suppression and cancer progression. Nat. Genet. 29: 117-129

123 Oft M., Akhurst R. J. and Balmain A. (2002) Metastasis is driven by sequential elevation of H-ras and Smad2 levels. Nat. Cell Biol. 4: 487-494

124 Bhowmick N. A., Ghiassi M., Bakin A., Aakre M., Lundquist C. A., Engel M. E. et al. (2001) Transforming growth factor-beta1 mediates epithelial to mesenchymal transdifferentiation through a RhoA-dependent mechanism. Mol. Biol. Cell 12: 27-36

125 Bernards R. and Weinberg R. A. (2002) A progression puzzle. Nature 418: 823

126 Paris P. L., Andaya A., Fridlyand J., Jain A. N., Weinberg V., Kowbel D. et al. (2004) Whole genome scanning identifies genotypes associated with recurrence and metastasis in prostate tumors. Hum. Mol. Genet. 13: 1303-1313

127 van de Vijver M. J., He Y. D., van’t Veer L. J., Dai H., Hart A. A., Voskuil D. W. et al. (2002) A gene-expression signature as a predictor of survival in breast cancer. N. Engl. J. Med. 347: 1999-2009

128 van't Veer L. J., Dai H., van de Vijver M. J., He Y. D., Hart A. A., Mao M. et al. (2002) Gene expression profiling predicts clinical outcome of breast cancer. Nature 415: 530-536

129 Ramaswamy S., Ross K. N., Lander E. S. and Golub T. R. (2003) A molecular signature of metastasis in primary solid tumors. Nat. Genet. 33: 49-54

130 Porter D. A., Krop I. E., Nasser S., Sgroi D., Kaelin C. M., Marks J. R. et al. (2001) A SAGE (serial analysis of gene expression) view of breast tumor progression. Cancer Res. 61: $5697-5702$

131 Klein C. A., Blankenstein T. J., Schmidt-Kittler O., Petronio M., Polzer B., Stoecklein N. H. et al. (2002) Genetic heterogeneity of single disseminated tumour cells in minimal residual cancer. Lancet 360: 683-689

132 Sternlicht M. D., Bissell M. J. and Werb Z. (2000) The matrix metalloproteinase stromelysin-1 acts as a natural mammary tumor promoter. Oncogene 19: 1102-1113

133 Minn A. J., Gupta G. P., Siegel P. M., Bos P. D., Shu W., Giri D. D. et al. (2005) Genes that mediate breast cancer metastasis to lung. Nature 436: $518-524$
134 Muller A., Homey B., Soto H., Ge N., Catron D., Buchanan M. E. et al. (2001) Involvement of chemokine receptors in breast cancer metastasis. Nature 410: $50-56$

135 Yang J., Mani S. A., Donaher J. L., Ramaswamy S., Itzykson R. A., Come C. et al. (2004) Twist, a master regulator of morphogenesis, plays an essential role in tumor metastasis. Cell 117: 927-939

136 Douma S., Van Laar T., Zevenhoven J., Meuwissen R., Van Garderen E. and Peeper D. S. (2004) Suppression of anoikis and induction of metastasis by the neurotrophic receptor TrkB. Nature 430: 1034-1039

137 Arthur W. T., Noren N. K. and Burridge K. (2002) Regulation of Rho family GTPases by cell-cell and cell-matrix adhesion. Biol. Res. 35: 239-246

138 Suwa H., Ohshio G., Imamura T., Watanabe G., Arii S., Imamura M. et al. (1998) Overexpression of the rhoC gene correlates with progression of ductal adenocarcinoma of the pancreas. Br. J. Cancer 77: 147-152

139 Kondo T., Sentani K., Oue N., Yoshida K., Nakayama H. and Yasui W. (2004) Expression of RHOC is associated with metastasis of gastric carcinomas. Pathobiology 71: 19-25

140 Hakem A., Sanchez-Sweatman O., You-Ten A., Duncan G., Wakeham A., Khokha R. et al. (2005) RhoC is dispensable for embryogenesis and tumor initiation but essential for metastasis. Genes Dev. 19: 1974-1979

141 Boire A., Covic L., Agarwal A., Jacques S., Sherifi S. and Kuliopulos A. (2005) PAR1 is a matrix metalloprotease-1 receptor that promotes invasion and tumorigenesis of breast cancer cells. Cell 120: 303-313

142 Even-Ram S. C., Maoz M., Pokroy E., Reich R., Katz B. Z., Gutwein P. et al. (2001) Tumor cell invasion is promoted by activation of protease activated receptor- 1 in cooperation with the alpha vbeta 5 integrin. J. Biol. Chem. 276: 10952-10962

143 Rickles F. R., Levine M. and Edwards R. L. (1992) Hemostatic alterations in cancer patients. Cancer Metastasis Rev. 11: $237-248$

144 Shi X., Gangadharan B., Brass L. F., RufW. and Mueller B. M. (2004) Protease-activated receptors (PAR1 and PAR2) contribute to tumor cell motility and metastasis. Mol. Cancer Res. 2: $395-402$

145 Bhowmick N. A. and Moses H. L. (2005) Tumor-stroma interactions. Curr. Opin. Genet. Dev. 15: 97-101

146 Carmeliet P. and Jain R. K. (2000) Angiogenesis in cancer and other diseases. Nature 407: 249-257

147 Folkman J. (2003) Fundamental concepts of the angiogenic process. Curr. Mol. Med. 3: 643-651

148 Bergers G. and Benjamin L. E. (2003) Tumorigenesis and the angiogenic switch. Nat. Rev. Cancer 3: 401-410

149 Joyce J. A. (2005) Therapeutic targeting of the tumor microenvironment. Cancer Cell 7: 513-520

150 Benoy I. H., Salgado R., Elst H., Van Dam P., Weyler J., Van Marck E. et al. (2005) Relative microvessel area of the primary tumour and not lymph node status, predicts the presence of bone marrow micrometastases detected by reverse transcriptase polymerase chain reaction in patients with clinically non-metastatic breast cancer. Breast Cancer Res. 7: R210 R219

151 Fukata S., Inoue K., Kamada M., Kawada C., Furihata M., Ohtsuki Y. et al. (2005) Levels of angiogenesis and expression of angiogenesis-related genes are prognostic for organspecific metastasis of renal cell carcinoma. Cancer 103: 931942

152 Fox S. B., Gasparini G. and Harris A. L. (2001) Angiogenesis: pathological, prognostic and growth-factor pathways and their link to trial design and anticancer drugs. Lancet Oncol. 2: 278-289

153 Guang-Wu H., Sunagawa M., Jie-En L., Shimada S., Gang Z., Tokeshi Y. et al. (2000) The relationship between microvessel density, the expression of vascular endothelial growth factor 
(VEGF) and the extension of nasopharyngeal carcinoma. Laryngoscope 110: 2066-2069

154 Huang S. P., Wu M. S., Wang H. P., Yang C. S., Kuo M. L. and Lin J. T. (2002) Correlation between serum levels of interleukin- 6 and vascular endothelial growth factor in gastric carcinoma. J. Gastroenterol. Hepatol. 17: 1165-1169

155 Tokunaga T., Nakamura M., Oshika Y., Abe Y., Ozeki Y., Fukushima Y. et al. (1999) Thrombospondin 2 expression is correlated with inhibition of angiogenesis and metastasis of colon cancer. Br. J. Cancer 79: 354-359

156 Khanna C., Jaboin J. J., Drakos E., Tsokos M. and Thiele C. J. (2002) Biologically relevant orthotopic neuroblastoma xenograft models: primary adrenal tumor growth and spontaneous distant metastasis. In Vivo 16: 77-85

157 Rofstad E. K. and Halsor E. F. (2000) Vascular endothelial growth factor, interleukin 8 , platelet-derived endothelial cell growth factor and basic fibroblast growth factor promote angiogenesis and metastasis in human melanoma xenografts. Cancer Res. 60: 4932-4938

158 Stearns M. E., Garcia F. U., Fudge K., Rhim J. and Wang M. (1999) Role of interleukin 10 and transforming growth factor betal in the angiogenesis and metastasis of human prostate primary tumor lines from orthotopic implants in severe combined immunodeficiency mice. Clin. Cancer Res. 5: $711-720$

159 Polnaszek N., Kwabi-Addo B., Peterson L. E., Ozen M., Greenberg N. M., Ortega S. et al. (2003) Fibroblast growth factor 2 promotes tumor progression in an autochthonous mouse model of prostate cancer. Cancer Res. 63: 5754-5760

160 Nguyen M., Lee M. C., Wang J. L., Tomlinson J. S., Shao Z. M., Alpaugh M. L. et al. (2000) The human myoepithelial cell displays a multifaceted anti-angiogenic phenotype. Oncogene 19: 3449-3459

161 Chen C. T., Lin J., Li Q., Phipps S. S., Jakubczak J. L., Stewart D. A. et al. (2000) Antiangiogenic gene therapy for cancer via systemic administration of adenoviral vectors expressing secretable endostatin. Hum. Gene Ther. 11: 1983-1996

162 de Lorenzo M. S., Ripoll G. V., Yoshiji H., Yamazaki M., Thorgeirsson U. P., Alonso D. F. et al. (2003) Altered tumor angiogenesis and metastasis of B16 melanoma in transgenic mice overexpressing tissue inhibitor of metalloproteinases- 1 . In Vivo 17: 45-50

163 Gannon G., Mandriota S. J., Cui L., Baetens D., Pepper M. S. and Christofori G. (2002) Overexpression of vascular endothelial growth factor-A165 enhances tumor angiogenesis but not metastasis during beta-cell carcinogenesis. Cancer Res. 62: 603-608

164 Viloria-Petit A., Miquerol L., Yu J. L., Gertsenstein M., Sheehan C., May L. et al. (2003) Contrasting effects of VEGF gene disruption in embryonic stem cell-derived versus oncogeneinduced tumors. EMBO J. 22: 4091-4102

165 Sauter E. R., Nesbit M., Watson J. C., Klein-Szanto A., Litwin S. and Herlyn M. (1999) Vascular endothelial growth factor is a marker of tumor invasion and metastasis in squamous cell carcinomas of the head and neck. Clin. Cancer Res. 5: 775782

166 Nathanson S. D. (2003) Insights into the mechanisms of lymph node metastasis. Cancer 98: 413-423

167 Pepper M. S., Tille J. C., Nisato R. and Skobe M. (2003) Lymphangiogenesis and tumor metastasis. Cell Tissue Res. 314: 167-177

168 Franchi A., Gallo O., Massi D., Baroni G. and Santucci M. (2004) Tumor lymphangiogenesis in head and neck squamous cell carcinoma: a morphometric study with clinical correlations. Cancer 101: 973-978

169 Dadras S. S., Paul T., Bertoncini J., Brown L. F., Muzikansky A., Jackson D. G. et al. (2003) Tumor lymphangiogenesis: a novel prognostic indicator for cutaneous melanoma metastasis and survival. Am. J. Pathol. 162: 1951-1960
170 Alitalo K. and Carmeliet P. (2002) Molecular mechanisms of lymphangiogenesis in health and disease. Cancer Cell 1:219 227

171 Saharinen P., Tammela T., Karkkainen M. J. and Alitalo K. (2004) Lymphatic vasculature: development, molecular regulation and role in tumor metastasis and inflammation. Trends Immunol. 25: 387-395

172 Jia Y. T., Li Z. X., He Y. T., Liang W., Yang H. C. and Ma H. J. (2004) Expression of vascular endothelial growth factor-C and the relationship between lymphangiogenesis and lymphatic metastasis in colorectal cancer. World J. Gastroenterol. 10: $3261-3263$

173 Suzuki K., Morita T. and Tokue A. (2005) Vascular endothelial growth factor-C (VEGF-C) expression predicts lymph node metastasis of transitional cell carcinoma of the bladder. Int. J. Urol. 12: 152-158

174 Kurahara H., Takao S., Maemura K., Shinchi H., Natsugoe S. and Aikou T. (2004) Impact of vascular endothelial growth factor-C and -D expression in human pancreatic cancer: its relationship to lymph node metastasis. Clin. Cancer Res. 10: 8413-8420

175 Kawakami M., Furuhata T., Kimura Y., Yamaguchi K., Hata F., Sasaki K. et al. (2003) Expression analysis of vascular endothelial growth factors and their relationships to lymph node metastasis in human colorectal cancer. J. Exp. Clin. Cancer Res. 22: 229-237

176 Kitadai Y., Kodama M., Cho S., Kuroda T., Ochiumi T., Kimura S. et al. (2005) Quantitative analysis of lymphangiogenic markers for predicting metastasis of human gastric carcinoma to lymph nodes. Int. J. Cancer 115: 388-392

177 Krishnan J., Kirkin V., Steffen A., Hegen M., Weih D., Tomarev S. et al. (2003) Differential in vivo and in vitro expression of vascular endothelial growth factor (VEGF)-C and VEGF-D in tumors and its relationship to lymphatic metastasis in immunocompetent rats. Cancer Res. 63: 713-722

178 Saharinen P. and Petrova T. V. (2004) Molecular regulation of lymphangiogenesis. Ann. N. Y. Acad. Sci. 1014: 76-87

179 Hanrahan V., Currie M. J., Gunningham S. P., Morrin H. R., Scott P. A., Robinson B. A. et al. (2003) The angiogenic switch for vascular endothelial growth factor (VEGF)-A, VEGF-B, VEGF-C and VEGF-D in the adenoma-carcinoma sequence during colorectal cancer progression. J. Pathol. 200: 183-194

180 McCarron S. L., Edwards S., Evans P. R., Gibbs R., Dearnaley D. P., Dowe A. et al. (2002) Influence of cytokine gene polymorphisms on the development of prostate cancer. Cancer Res. 62: 3369-3372

181 Powell D. W., Mifflin R. C., Valentich J. D., Crowe S. E., Saada J. I. and West A. B. (1999) Myofibroblasts. I. Paracrine cells important in health and disease. Am J Physiol 277: C1-C9

182 Orimo A., Gupta P. B., Sgroi D. C., Arenzana-Seisdedos F., Delaunay T., Naeem R. et al. (2005) Stromal fibroblasts present in invasive human breast carcinomas promote tumor growth and angiogenesis through elevated SDF-1/CXCL12 secretion. Cell 121: 335-348

183 Hayward S. W., Wang Y., Cao M., Hom Y. K., Zhang B., Grossfeld G. D. et al. (2001) Malignant transformation in a nontumorigenic human prostatic epithelial cell line. Cancer Res. 61: 8135-8142

184 De Wever O. and Mareel M. (2003) Role of tissue stroma in cancer cell invasion. J. Pathol. 200: 429-447

185 Elenbaas B. and Weinberg R. A. (2001) Heterotypic signaling between epithelial tumor cells and fibroblasts in carcinoma formation. Exp. Cell Res. 264: 169-184

186 Singh R. K., Bucana C. D., Gutman M., Fan D., Wilson M. R. and Fidler I. J. (1994) Organ site-dependent expression of basic fibroblast growth factor in human renal cell carcinoma cells. Am. J. Pathol. 145: 365-374

187 Nakajima M., Morikawa K., Fabra A., Bucana C. D. and Fidler I. J. (1990) Influence of organ environment on extracellular 
matrix degradative activity and metastasis of human colon carcinoma cells. J. Natl. Cancer Inst. 82: 1890-1898

188 Bhowmick N. A., Chytil A., Plieth D., Gorska A. E., Dumont N., Shappell S. et al. (2004) TGF-beta signaling in fibroblasts modulates the oncogenic potential of adjacent epithelia. Science 303: 848-851

189 Liang Z., Wu T., Lou H., Yu X., Taichman R. S., Lau S. K. et al. (2004) Inhibition of breast cancer metastasis by selective synthetic polypeptide against CXCR4. Cancer Res. 64: 43024308

190 McClain K. L. (1997) Immunodeficiency states and related malignancies. Cancer Treat. Res. 92: 39-61

191 Lake R. A. and Robinson B. W. (2005) Immunotherapy and chemotherapy - a practical partnership. Nat. Rev. Cancer 5: 397-405

192 Zou W. (2005) Immunosuppressive networks in the tumour environment and their therapeutic relevance. Nat. Rev. Cancer 5: $263-274$

193 Lingen M. W. (2001) Role of leukocytes and endothelial cells in the development of angiogenesis in inflammation and wound healing. Arch. Pathol. Lab. Med. 125: 67-71

194 Nathan C. (2002) Points of control in inflammation. Nature 420: $846-852$

195 Bottazzi B., Polentarutti N., Acero R., Balsari A., Boraschi D., Ghezzi P. et al. (1983) Regulation of the macrophage content of neoplasms by chemoattractants. Science 220: 210-212

196 Coussens L. M. and Werb Z. (2002) Inflammation and cancer. Nature 420: $860-867$

197 Balkwill F. (2004) Cancer and the chemokine network. Nat. Rev. Cancer 4: 540-550

198 Bingle L., Brown N. J. and Lewis C. E. (2002) The role of tumour-associated macrophages in tumour progression: implications for new anticancer therapies. J. Pathol. 196: 254-265

199 Liss C., Fekete M. J., Hasina R., Lam C. D. and Lingen M. W. (2001) Paracrine angiogenic loop between head-and-neck squamous-cell carcinomas and macrophages. Int. J. Cancer 93: 781-785

200 Skobe M., Hamberg L. M., Hawighorst T., Schirner M., Wolf G. L., Alitalo K. et al. (2001) Concurrent induction of lymphangiogenesis, angiogenesis and macrophage recruitment by vascular endothelial growth factor-C in melanoma. Am. J. Pathol. 159: 893-903

201 Ohno S., Inagawa H., Dhar D. K., Fujii T., Ueda S., Tachibana M. et al. (2003) The degree of macrophage infiltration into the cancer cell nest is a significant predictor of survival in gastric cancer patients. Anticancer Res. 23: 5015-5022

202 Shimura S., Yang G., Ebara S., Wheeler T. M., Frolov A. and Thompson T. C. (2000) Reduced infiltration of tumor-associated macrophages in human prostate cancer: association with cancer progression. Cancer Res. 60: $5857-5861$

203 Chen J. J., Lin Y. C., Yao P. L., Yuan A., Chen H. Y., Shun C. T. et al. (2005) Tumor-associated macrophages: the doubleedged sword in cancer progression. J. Clin. Oncol. 23: 953964

204 Dranoff G. (2004) Cytokines in cancer pathogenesis and cancer therapy. Nat. Rev. Cancer 4: 11-22

205 Gabrilovich D. I., Chen H. L., Girgis K. R., Cunningham H. T., Meny G. M., Nadaf S. et al. (1996) Production of vascular endothelial growth factor by human tumors inhibits the functional maturation of dendritic cells. Nat. Med. 2: 10961103

206 Gorelik L. and Flavell R. A. (2001) Immune-mediated eradication of tumors through the blockade of transforming growth factor-beta signaling in T cells. Nat. Med. 7: 1118-1122

207 Menetrier-Caux C., Montmain G., Dieu M. C., Bain C., Favrot M. C., Caux C. et al. (1998) Inhibition of the differentiation of dendritic cells from $\mathrm{CD} 34(+)$ progenitors by tumor cells: role of interleukin-6 and macrophage colony-stimulating factor. Blood 92: 4778-4791
208 Balkwill F. (2002) Tumor necrosis factor or tumor promoting factor? Cytokine Growth Factor Rev. 13: 135-141

209 Xu W., Liu L. Z., Loizidou M., Ahmed M. and Charles I. G. (2002) The role of nitric oxide in cancer. Cell Res. 12: 311320

210 O'Sullivan C., Lewis C. E., Harris A. L. and McGee J. O. (1993) Secretion of epidermal growth factor by macrophages associated with breast carcinoma. Lancet 342: 148-149

211 Ruohola J. K., Viitanen T. P., Valve E. M., Seppanen J. A., Loponen N. T., Keskitalo J. J. et al. (2001) Enhanced invasion and tumor growth of fibroblast growth factor $8 \mathrm{~b}$-overexpressing MCF-7 human breast cancer cells. Cancer Res. 61: 42294237

212 Nagy J., Curry G. W., Hillan K. J., McKay I. C., Mallon E., Purushotham A. D. et al. (1996) Hepatocyte growth factor/scatter factor expression and c-met in primary breast cancer. Surg. Oncol. 5: 15-21

213 Sunderkotter C., Steinbrink K., Goebeler M., Bhardwaj R. and Sorg C. (1994) Macrophages and angiogenesis. J. Leukoc. Biol. 55: 410-422

214 Leal J. A., Gangrade B. K., Kiser J. L., May J. V. and Keel B. A. (1991) Human mammary tumor cell proliferation: primary role of platelet-derived growth factor and possible synergism with human alpha-fetoprotein. Steroids 56: 247-251

215 Cursiefen C., Chen L., Borges L. P., Jackson D., Cao J., Radziejewski C. et al. (2004) VEGF-A stimulates lymphangiogenesis and hemangiogenesis in inflammatory neovascularization via macrophage recruitment. J. Clin. Invest. 113: $1040-1050$

216 Schoppmann S. F., Birner P., Stockl J., Kalt R., Ullrich R., Caucig C. et al. (2002) Tumor-associated macrophages express lymphatic endothelial growth factors and are related to peritumoral lymphangiogenesis. Am. J. Pathol. 161: 947-956

217 Maruyama K., Ii M., Cursiefen C., Jackson D. G., Keino H., Tomita M. et al. (2005) Inflammation-induced lymphangiogenesis in the cornea arises from CD11b-positive macrophages. J. Clin. Invest. 115: 2363-2372

218 Coussens L. M., Tinkle C. L., Hanahan D. and Werb Z. (2000) MMP-9 supplied by bone marrow-derived cells contributes to skin carcinogenesis. Cell 103: 481-490

219 Huang S., Van Arsdall M., Tedjarati S., McCarty M., Wu W., Langley R. et al. (2002) Contributions of stromal metalloproteinase- 9 to angiogenesis and growth of human ovarian carcinoma in mice. J. Natl. Cancer Inst. 94: 1134-1142

220 van Netten J. P., Ashmead B. J., Parker R. L., Thornton I. G., Fletcher C., Cavers D. et al. (1993) Macrophage-tumor cell associations: a factor in metastasis of breast cancer? J. Leukoc. Biol. 54: 360-362

221 Jaiswal M., LaRusso N. F. and Gores G. J. (2001) Nitric oxide in gastrointestinal epithelial cell carcinogenesis: linking inflammation to oncogenesis. Am. J. Physiol. Gastrointest. Liver Physiol. 281: G626-G634

222 Karre K., Ljunggren H. G., Piontek G. and Kiessling R. (1986) Selective rejection of H-2-deficient lymphoma variants suggests alternative immune defence strategy. Nature 319: $675-678$

223 Smyth M. J., Thia K. Y., Street S. E., Cretney E., Trapani J. A., Taniguchi M. et al. (2000) Differential tumor surveillance by natural killer (NK) and NKT cells. J. Exp. Med. 191: 661668

224 Colucci F., Di Santo J. P. and Leibson P. J. (2002) Natural killer cell activation in mice and men: different triggers for similar weapons? Nat Immunol. 3: 807-813

225 Whiteside T. L., Vujanovic N. L. and Herberman R. B. (1998) Natural killer cells and tumor therapy. Curr. Top. Microbiol. Immunol. 230: 221-244

226 Smyth M. J., Thia K. Y., Cretney E., Kelly J. M., Snook M. B., Forbes C. A. et al. (1999) Perforin is a major contributor to NK cell control of tumor metastasis. J. Immunol. 162: 6658-6662 
227 Hashimoto W., Takeda K., Anzai R., Ogasawara K., Sakihara H., Sugiura K. et al. (1995) Cytotoxic NK1.1 Ag+ alpha beta $\mathrm{T}$ cells with intermediate TCR induced in the liver of mice by IL-12. J. Immunol. 154: 4333-4340

228 Li C., Bai X., Wang S., Tomiyama-Miyaji C., Nagura T., Kawamura T. et al. (2004) Immunopotentiation of NKT cells by low-protein diet and the suppressive effect on tumor metastasis. Cell. Immunol. 231: 96-102

229 Smyth M. J., Hayakawa Y., Takeda K. and Yagita H. (2002) New aspects of natural-killer-cell surveillance and therapy of cancer. Nat. Rev. Cancer 2: 850-861

230 Conejo-Garcia J. R., Benencia F., Courreges M. C., Kang E., Mohamed-Hadley A., Buckanovich R. J. et al. (2004) Tumorinfiltrating dendritic cell precursors recruited by a beta-defensin contribute to vasculogenesis under the influence of Vegf-A. Nat. Med. 10: 950-958

231 Zou W., Machelon V., Coulomb-L'Hermin A., Borvak J., Nome F., Isaeva T. et al. (2001) Stromal-derived factor-1 in human tumors recruits and alters the function of plasmacytoid precursor dendritic cells. Nat. Med. 7: 1339-1346

232 Bell D., Chomarat P., Broyles D., Netto G., Harb G. M., Lebecque S. et al. (1999) In breast carcinoma tissue, immature dendritic cells reside within the tumor, whereas mature dendritic cells are located in peritumoral areas. J. Exp. Med. 190: $1417-1426$

233 Troy A., Davidson P., Atkinson C. and Hart D. (1998) Phenotypic characterisation of the dendritic cell infiltrate in prostate cancer. J. Urol. 160: 214-219

234 Troy A. J., Summers K. L., Davidson P. J., Atkinson C. H. and Hart D. N. (1998) Minimal recruitment and activation of dendritic cells within renal cell carcinoma. Clin. Cancer Res. 4: 585-593

235 Yang L. and Carbone D. P. (2004) Tumor-host immune interactions and dendritic cell dysfunction. Adv. Cancer Res. 92: $13-27$

236 Lanzavecchia A. and Sallusto F. (2001) The instructive role of dendritic cells on $\mathrm{T}$ cell responses: lineages, plasticity and kinetics. Curr. Opin. Immunol. 13: 291-298

237 Banchereau J. and Palucka A. K. (2005) Dendritic cells as therapeutic vaccines against cancer. Nat. Rev. Immunol. 5: 296-306
238 Curiel T. J., Wei S., Dong H., Alvarez X., Cheng P., Mottram P. et al. (2003) Blockade of B7-H1 improves myeloid dendritic cell-mediated antitumor immunity. Nat. Med. 9: 562-567

239 Iwai Y., Terawaki S. and Honjo T. (2005) PD-1 blockade inhibits hematogenous spread of poorly immunogenic tumor cells by enhanced recruitment of effector T cells. Int. Immunol. 17: 133-144

240 Curiel T. J., Cheng P., Mottram P., Alvarez X., Moons L., Evdemon-Hogan M. et al. (2004) Dendritic cell subsets differentially regulate angiogenesis in human ovarian cancer. Cancer Res. 64: 5535-5538

241 Conejo-Garcia J. R., Buckanovich R. J., Benencia F., Courreges M. C., Rubin S. C., Carroll R. G. et al. (2005) Vascular leukocytes contribute to tumor vascularization. Blood 105: 679-681

242 Fallarino F., Grohmann U., Bianchi R., Vacca C., Fioretti M. C. and Puccetti P. (2000) Th1 and Th2 cell clones to a poorly immunogenic tumor antigen initiate CD8+ T cell-dependent tumor eradication in vivo. J. Immunol. 165: 5495-5501

243 Knutson K. L. and Disis M. L. (2005) Tumor antigen-specific $\mathrm{T}$ helper cells in cancer immunity and immunotherapy. Cancer Immunol. Immunother. 54: 721-728

244 Curiel T. J., Coukos G., Zou L., Alvarez X., Cheng P., Mottram P. et al. (2004) Specific recruitment of regulatory T cells in ovarian carcinoma fosters immune privilege and predicts reduced survival. Nat. Med. 10: 942-949

245 Matar P., Rozados V. R., Gonzalez A. D., Dlugovitzky D. G., Bonfil R. D. and Scharovsky O. G. (2000) Mechanism of antimetastatic immunopotentiation by low-dose cyclophosphamide. Eur. J. Cancer 36: 1060-1066

246 Schirrmacher V. (2005) T cell-mediated immunotherapy of metastases: state of the art in 2005. Expert Opin. Biol. Ther. 5: $1051-1068$

247 Gilboa E. (2004) The promise of cancer vaccines. Nat. Rev. Cancer 4: 401-411

248 Nyhus J. K., Wolford C. C., Friece C. R., Nelson M. B., Sampsel J. W. and Barbera-Guillem E. (2001) IgG-recognizing shed tumor-associated antigens can promote tumor invasion and metastasis. Cancer Immunol. Immunother. 50: 361-372

249 de Visser K. E., Korets L. V. and Coussens L. M. (2005) De novo carcinogenesis promoted by chronic inflammation is B lymphocyte dependent. Cancer Cell 7: 411-423 